\title{
Influence of Mo and Fe on Photosynthetic and Nitrogenase Activities of Nitrogen-Fixing Cyanobacteria under Nitrogen Starvation
}

\author{
Asemgul K. Sadvakasova ${ }^{1}$, Bekzhan D. Kossalbayev ${ }^{1,2, * \mathbb{D}}$, Aziza I. Token ${ }^{1}$, Meruert O. Bauenova ${ }^{1}$, \\ Jingjing Wang ${ }^{3}$, Bolatkhan K. Zayadan ${ }^{1}$, Huma Balouch ${ }^{1}$, Saleh Alwasel ${ }^{4}$ (D), Yoong Kit Leong ${ }^{5}$, \\ Jo-Shu Chang ${ }^{5,6,7}$ and Suleyman I. Allakhverdiev ${ }^{1,4,8, *(D)}$
}

check for updates

Citation: Sadvakasova, A.K.; Kossalbayev, B.D.; Token, A.I.; Bauenova, M.O.; Wang, J.; Zayadan, B.K.; Balouch, H.; Alwasel, S.; Leong, Y.K.; Chang, J.-S.; et al. Influence of $\mathrm{Mo}$ and $\mathrm{Fe}$ on Photosynthetic and Nitrogenase Activities of Nitrogen-Fixing Cyanobacteria under Nitrogen Starvation. Cells 2022, 11, 904. https://doi.org/10.3390/ cells11050904

Academic Editor: Stanislaw Karpinski

Received: 6 February 2022

Accepted: 2 March 2022

Published: 5 March 2022

Publisher's Note: MDPI stays neutral with regard to jurisdictional claims in published maps and institutional affiliations.

Copyright: (C) 2022 by the authors. Licensee MDPI, Basel, Switzerland. This article is an open access article distributed under the terms and conditions of the Creative Commons Attribution (CC BY) license (https:// creativecommons.org/licenses/by/ $4.0 /)$.
1 Faculty of Biology and Biotechnology, Al-Farabi Kazakh National University, Al-Farabi Avenue 71, Almaty 050038, Kazakhstan; asem182010@gmail.com (A.K.S.); t.aziza_93@mail.ru (A.I.T.); bauyen.meruyert@gmail.com (M.O.B.); zbolatkhan@gmail.com (B.K.Z.); huma@comsats.org (H.B.)

2 Department of Chemical and Biochemical Engineering, Geology and Oil-Gas Business Institute Named after K. Turyssov, Satbayev University, Almaty 050043, Kazakhstan

3 Tianjin Institute of Industrial Biotechnology, Chinese Academy of Sciences, No. 32, West 7th Road, Tianjin Airport Economic Area, Tianjin 300308, China; wang_jj@tib.cas.cn

4 College of Science, King Saud University, Riyadh 12372, Saudi Arabia; salwasel@ksu.edu.sa

5 Department of Chemical and Materials Engineering, Tunghai University, Taichung 407, Taiwan; yoongkitleong1014@gmail.com (Y.K.L.); changjs@mail.ncku.edu.tw (J.-S.C.)

6 Research Center for Smart Sustainable Circular Economy, Tunghai University, Taichung 407, Taiwan

7 Department of Chemical Engineering, National Cheng Kung University, Tainan 701, Taiwan

8 Controlled Photobiosynthesis Laboratory, K.A. Timiryazev Institute of Plant Physiology, Russian Academy of Sciences, Botanicheskaya Street 35, 127276 Moscow, Russia

* Correspondence: kossalbayev.bekzhan@gmail.com (B.D.K.); suleyman.allakhverdiev@gmail.com (S.I.A.)

\begin{abstract}
The potential of cyanobacteria to perform a variety of distinct roles vital for the biosphere, including nutrient cycling and environmental detoxification, drives interest in studying their biodiversity. Increasing soil erosion and the overuse of chemical fertilizers are global problems in developed countries. The option might be to switch to organic farming, which entails largely the use of biofertilisers. Cyanobacteria are prokaryotic, photosynthetic organisms with considerable potential, within agrobiotechnology, to produce biofertilisers. They contribute significantly to plant drought resistance and nitrogen enrichment in the soil. This study sought, isolated, and investigated nitrogen-fixing cyanobacterial strains in rice fields, and evaluated the effect of Mo and Fe on photosynthetic and nitrogenase activities under nitrogen starvation. Cyanobacterial isolates, isolated from rice paddies in Kazakhstan, were identified as Trichormus variabilis K-31 (MZ079356), Cylindrospermum badium J-8 (MZ079357), Nostoc sp. J-14 (MZ079360), Oscillatoria brevis SH-12 (MZ090011), and Tolypothrix tenuis J-1 (MZ079361). The study of the influence of various concentrations of Mo and Fe on photosynthetic and nitrogenase activities under conditions of nitrogen starvation revealed the optimal concentrations of metals that have a stimulating effect on the studied parameters.
\end{abstract}

Keywords: cyanobacteria; heavy metals; photosynthesis; nitrogenase; heterocyst

\section{Introduction}

The most important direction in the development of organic agriculture is the creation of microbial biotechnologies that help maintain fertility and intensify agricultural production. Soil fertility is directly related to the diversity, quantity, and activity of the soil microbiota, which determine the transformation, migration, and accumulation of substances in the soil ecosystem, and provide plants with all necessary assailable nutrients. At the same time, it is known that the increase in crop yields largely depends on access to mineral nutrients, especially nitrogen. The natural sources of nitrogen in the soil are microorganisms, which can fix molecular nitrogen from the atmosphere [1-4]. 
In this context, one of the most interesting groups of microorganisms are cyanobacteria, which, in addition to the ability to fix nitrogen, have a wide range of adaptations to different soil and hydrothermal conditions [5-7]. Herewith, both types of cyanobacteria (with heterocysts and without them) have the ability to fix nitrogen. However, in heterocystous cyanobacteria, the processes of photosynthesis and nitrogen fixation occur simultaneously and independently of the time of day, while in non-heterocystous cyanobacteria, these processes occur separately: nitrogen fixation, at night; photosynthesis during the day [8]. In the cyanobacterial species that form heterocysts, the nitrogenase is located in the heterocyst and is, thus, protected from the inhibitory effects of oxygen [9-13]. They are more attractive in terms of productivity and can enrich the soil with $20-30 \mathrm{~kg} \mathrm{~N} \mathrm{ha}^{-1}$ per year, which is a great economic advantage for agriculture. In addition, they are technologically advanced, can grow on cheap media without sources of organic compounds and mineral nitrogen, and do not require expensive equipment $[14,15]$. Considering the main factors affecting nitrogenase activity, it is worth outlining the role of biogenic metals in nitrogenase enzyme cofactors that determine the intensity of nitrogen fixation by free-living cyanobacteria [16,17].

Despite the large amount of data available in the literature indicating the high metabolic potential of cyanobacteria in nitrogen fixation, there are still some problems related to their productivity that limit their widespread use in agro-biotechnology. Therefore, the attention given to this group of organisms is focused on the study of the basic cultivation conditions that increase their nitrogen fixation abilities.

In this regard, scientific research aimed at potentially enhancing the nitrogen-fixing ability of cyanobacteria is currently very relevant. Primarily, research in this area should focus on finding new, more productive strains of nitrogen-fixing cyanobacteria and developing new approaches to increase the efficiency of their metabolic activity.

Therefore, this work aims to select and study new strains of nitrogen-fixing cyanobacteria. The article demonstrates the results of isolation, investigation, and identification of five cyanobacterial strains isolated from rice paddies in Kazakhstan and the influence of Mo and Fe on their photosynthetic and nitrogenase activity.

\section{Materials and Methods}

\subsection{Research Objects}

Five different strains of cyanobacteria, including Nostoc sp. (J-14), Cylindrospermum sp. (J-8), Anabaena variabilis (K-31), Oscillatoria brevis (SH-12), and Tolypothrix tenuis (J-1), were isolated from the Kyzylorda region. The strains were isolated from the rice fields and aquatic ecosystems of the Zhanakorgan and Shieli districts of the Kyzylorda region (rice paddies of Avangard, Akzhol, and Zhayilma villages, and water basins adjacent to rice fields, i.e., the tributaries of the Syr-Darya river: Kuday Kul, Zhayilma).

\subsection{Isolation and Cultivation of Cyanobacterial Strains}

Eighteen water samples and twenty-six composite samples of soil and cyanobacterial mats collected from the surface of plants using classical algological methods served as material for this study. Identifiers of freshwater microalgae and cyanobacteria were used to determine the species. In order to obtain enrichment cultures of cyanobacteria, $5 \mathrm{~mL}$ of aliquot samples were placed in $100 \mathrm{~mL}$ flasks containing $5 \mathrm{~mL}$ of BG-11 [18], Allen [19], Bold basal liquid [20] culture medium with the addition of cycloheximide (Biochem Chemopharma, Cosne-Cours-sur-Loire, France) at a concentration of $50 \mu \mathrm{g} \mathrm{mL}^{-1}$ to inhibit the growth of eukaryotes. Simultaneously, samples were inoculated into Petri dishes with solid medium (1\% agar) BG-11. Cultivation was carried out in parallel at temperatures of $18-22{ }^{\circ} \mathrm{C}$ with a constant illumination of $50 \mu \mathrm{mol}$ (photons) $\mathrm{m}^{-2} \mathrm{~s}^{-1}$. Unialgal cultures of cyanobacteria were obtained through the periodic inoculation of the enrichment culture on solid nutrient medium BG-11, Allen, Gromov, and Bold, using capillary pipettes to separate the cyanobacterial filaments from the mixed microbial suspension. Several antibiotics (penicillin, gentamicin, tetracycline, neomycin, ampicillin, chloramphenicol, and 
kanamycin) at different concentrations from 1500 unit (U) $\mathrm{mL}^{-1}$ to $25,000 \mathrm{U} \mathrm{mL}^{-1}$ and their combinations with a total concentration of $20,000 \mathrm{U} \mathrm{mL}^{-1}$ were used to purify isolated cyanobacterial cultures from satellite bacteria. The calculated concentrations of antibiotics were added to the culture media after sterilization. The strains of isolated cyanobacteria were cultured on liquid and agar nutrient media of standard composition BG-11 and Allen in flasks in the luminostat. Preliminary morphological identification was performed under a light microscope (Micro Optix C600, Wiener Neudorf, Austria). Morphological identification was based on some characteristic morphological features, such as cell size, shape, location of cells, presence or absence of mucus, etc., using taxonomic literature and various photo galleries. The determination of the species composition of phototrophic eukaryotes was based on morphological and cultural characteristics using various determinants [21,22]. Before conducting an experiment, the cyanobacterial culture was subcultured from the liquid medium with the stored culture on Petri dishes with a freshly prepared nutrient medium of the same composition.

\subsection{Molecular Identification of Cyanobacterial Strains}

Cyanobacterial species were identified using molecular genetic research methods by sequencing the conserved DNA locus. To accomplish the tasks assigned, the following steps were performed: the isolation of genomic DNA, sample preparation and polymerase chain reaction, DNA sequencing for a fragment of the conserved locus, and an analysis of the nucleotide sequence of the conserved 16S rRNA locus [23].

\subsubsection{Isolation of Genomic DNA of Cyanobacteria}

Genomic DNA was isolated following the protocol proposed by Dale et al. [24]. Cyanobacterial cells were pelleted via centrifugation at $4000 \times g$ for $5 \mathrm{~min}$, the supernatant was removed, and the cells were suspended in $1 \mathrm{~mL}$ of extraction buffer with the following composition: $200 \mathrm{mmol}$ Tris- $\mathrm{HCl}$ ( $\mathrm{pH}-8.0), 400 \mathrm{mmol} \mathrm{LiCl}, 25 \mathrm{mM}$ EDTA, and $1 \%$ SDS. Acid-treated glass beads with a diameter of 425-600 $\mu \mathrm{m}$ (Sigma-Aldrich, Darmstadt, Germany) were added to the suspension. The resulting suspension was shaken vigorously for $30 \mathrm{~s}$ and then incubated on ice for $30 \mathrm{~s}$. This procedure was repeated 5 times. The resulting mixture was centrifuged at $3000 \times g$ for $15 \mathrm{~min}$ at $4{ }^{\circ} \mathrm{C}$. The supernatant was then transferred to a sterile microtube containing $600 \mu \mathrm{L}$ of ice-cold isopropanol and mixed by pipetting, then centrifuged at $16,000 \times g$ for $20 \mathrm{~min}$ at $4{ }^{\circ} \mathrm{C}$. The precipitate was dissolved in $100 \mu \mathrm{L}$ TE buffer ( $2 \mathrm{mmol}$ Tris- $\mathrm{HCl}$ ( $\mathrm{pH}-8.0), 1 \mathrm{mmol}$ EDTA). Then, $10 \mu \mathrm{L} 3 \mathrm{M}$ sodium acetate (pH-5.2) and $300 \mu \mathrm{L}$ of $96 \%$ ethanol were added and incubated at $-20^{\circ} \mathrm{C}$ for $2 \mathrm{~h}$. The precipitate was centrifuged. Another round of centrifugation was performed for 30 min with $16,000 \times g$ at $4{ }^{\circ} \mathrm{C}$. The pellet was washed with $70 \%$ ethanol, oven-dried, and dissolved in $50 \mu \mathrm{L}$ TE buffer. DNA concentration was determined using a Nanovue plus spectrophotometer (Biochrom, Boston, MA, USA). The concentration of isolated genomic DNA was adjusted to $100 \mathrm{ng} \mu \mathrm{L}^{-1}$.

\subsubsection{Sample Preparation and Polymerase Chain Reaction}

The ribosomal DNA gene was selected as a conservative DNA locus for the cyanobacterial identification. The amplification of a $16 \mathrm{~S}$ rRNA gene fragment from bacterial genomic DNA was performed using primers: 8f, 806r, M23f, M23'f, 27f, 1492r, 1525r [25-27]. The separation of the amplification products was carried out via DNA electrophoresis using $1 \%$ agarose gel in TAE buffer containing ethidium bromide $\left(15 \mu \mathrm{g} \mathrm{mL}^{-1}\right)$. The resulting PCR products were treated with a mixture of Exol exonuclease and FastAP alkaline phosphatase to remove the remaining primers and dNTPs. To $10 \mu \mathrm{L}$ of each amplicon, $1 \mu \mathrm{L}$ of Exol and FastAP was added and incubated for $30 \mathrm{~min}$ at $37^{\circ} \mathrm{C}$. The inactivation of enzymes was carried out at $85^{\circ} \mathrm{C}$ for $15 \mathrm{~min}$ [28]. 


\subsubsection{DNA Sequencing Using the Fragment of the Conserved Locus}

DNA sequencing using the Sanger method was used to determine the nucleotide sequence of the conserved locus [29]. The analysis of chromatograms and their comparison with the reference sequence was carried out using the VectorNTI version 11 software package and the NCBI database using the BLAST (Basic Local Alignment Search Tool) service [30].

\subsection{Methods for Quantification of Microalgal Cells and Determination of Biomass Growth Productivity}

The change in the concentration of cyanobacterial biomass was determined by measuring the optical density on a PD-303UV spectrophotometer (Apel, Saitama, Japan) at a wavelength of 540-590 nm. The biomass productivity was determined according to Tsarenko et al. [31]. The cells were precipitated using a 5810R centrifuge (Eppendorf, Hamburg, Germany) at $5000 \times g$ for $5 \mathrm{~min}$ at $25{ }^{\circ} \mathrm{C}$. The growth rate coefficient of the cyanobacterial cultures was calculated based on the increase in the cell number in the experimental vessels, taking into account the initial cell number and the cell number after a certain time.

\subsection{Determination of the Heterocyst Formation Frequency}

The frequency of heterocyst formation was analysed on nitrogen-free $\mathrm{BG}_{0}-11$ [32] medium, and the control was a BG-11 nutrient medium with a standard composition. Before the experiment, the cultures were kept in a stationary phase without nutrients for 3 days to minimize the effects of the previous BG-11 starting medium on the growth of the cyanobacteria studied. Then, the cyanobacterial cells were centrifuged in the 5810R centrifuge at $1000 \times g$ for $10 \mathrm{~min}$ and the pellets were washed twice in saline solution to remove residual $\mathrm{N}$ and $\mathrm{P}$ from the cell surface. Cells were then incubated in flasks containing two versions of fresh media-BG- 11 and $\mathrm{BG}_{0}-11$ without $\mathrm{N}-$ at the same temperature and light intensity as described above. The frequency of heterocyst appearance was recorded daily for 9 days under a light microscope (Micro Optix OPTIX C600, Wiener Neudorf, Austria) at magnifications of 200 and 400 . For this purpose, $4 \mathrm{~mL}$ of the sample was taken with a micropipette, and a crushed droplet was prepared and analysed. Heterocysts were identified by their thickened cell wall, pale colour, and the formation of the poles compared to neighbouring cells [33]. The frequency of heterocysts was calculated as the percentage of heterocyst density to the total density of vegetative cells when at least 10 fields of view were counted per sample. Thus, the number of vegetative cells per heterocyst was determined for 10 heterocysts, and the data are expressed as mean \pm standard deviation. If there were not enough cyanobacterial cells to count 10 heterocysts, the data were noted as too small to count.

\subsection{Determination of Photosynthetic Activity}

Chlorophyll fluorescence parameters were measured using a Multi-function Plant Efficiency Analyzer (M-PEA-2, Hansatech Instruments, King's Lynn, UK) after $24 \mathrm{~h}$ of cultivation. The following fluorescence parameters were recorded during the experiments: $\mathrm{F}_{0}$ is the fluorescence value at open reaction centres, and $F_{m}$ is the maximum fluorescence after a series of light flashes saturate the photosynthesis reaction centres. Before measurement, samples were kept in the dark for $15 \mathrm{~min}$. These measured quantities were used to calculate the following parameters [34,35]:

$\mathrm{F}_{\mathrm{V}}=\mathrm{F}_{\mathrm{m}}-\mathrm{F}_{0}$ is the maximum variable fluorescence;

$\mathrm{F}_{\mathrm{V}} / \mathrm{F}_{\mathrm{m}}$ is the maximum quantum yield of PSII of the primary photochemical reaction in open PSII reaction centres: $\mathrm{F}_{\mathrm{V}} / \mathrm{F}_{\mathrm{m}}=\varphi$ Po.

All measurements were carried out in at least five repetitions. The figures show data of average values. 


\subsection{Determination of Nitrogenase Activity Using the Acetylene Method}

The cultures of cyanobacteria were cultivated in the light until the beginning of the stationary phase of the cells. Then, they were centrifuged at $16,000 \times g$ for $20 \mathrm{~min}$ at $4{ }^{\circ} \mathrm{C}$. The obtained biomass was adjusted to $\mathrm{OD}_{720}=1.5$, then $15 \mathrm{~mL}$ thick biomass was transferred to $25 \mathrm{~mL}$ GC vial. Next, a gas mixture of $10 \%$ acetylene and $90 \%$ argon was introduced into the GC vial within $30 \mathrm{~min}$ [36]. The cells inside the vial were cultured for 1, $2,4,8,24$, and $32 \mathrm{~h}$ at a photosynthetic photon flux density of $70 \mu \mathrm{mol}$ (photons) $\mathrm{m}^{-2} \mathrm{~s}^{-1}$. After incubation, $500 \mu \mathrm{L}$ gas samples were withdrawn and the concentration of ethylene in the gas mixture was determined. The redox activity of acetylene was determined on gas chromatograph GC-15A (Shimadzu, Kyoto, Japan) in the form of nmol ethylene $\mathrm{mg}^{-1} \mathrm{DW}$ (dry weight) $\mathrm{h}^{-1}$.

\subsection{Effect of Different Concentrations of Mo and Fe on Nitrogenase Activity}

The influence of these metals on the cultures was studied in Allen's medium. Of the metals studied, Mo $(0.017 \mu \mathrm{mol})$ is present in this medium as a trace element in trace amounts and Fe $(0.36 \mu \mathrm{mol})$ is present in an insignificant concentration. The study of the stimulatory effect of these metals on nitrogenase and photosynthetic activities was carried out with their additional introduction at different concentrations. Both metals were not excluded from the medium because they are of crucial importance, since $\mathrm{Fe}$, in addition to the process of nitrogen fixation, is also necessary for cell growth, in particular for the processes of photosynthesis and respiration.

Salt $\left(\mathrm{FeCl}_{3} \times 6 \mathrm{H}_{2} \mathrm{O}\right)$ was added to the nutrient medium in concentrations of 1,5 , 10 , and $15 \mu \mathrm{mol}$ and $\mathrm{Na}_{2} \mathrm{MoO}_{4}$ in concentrations of $0.1,0.5$, and $5 \mu \mathrm{mol}$. The control for all variants of the experiment was the Allen $_{0}$ medium (without nitrogen source), which contained Mo and Fe in concentrations equal to the composition of the standard medium. The cyanobacterial cultures were first cultured in Allen's medium for 7 days under light at a temperature of $26{ }^{\circ} \mathrm{C}$, then the cultures were transferred to Allen 0 medium, which also contained various concentrations of metals, and then the strains were cultured for an additional 7 days until anaerobic conditions were established and the amount of ethylene was recorded. Nitrogenase activity was determined after 1, 2, 4, 8, 24, and $32 \mathrm{~h}$.

\subsection{Pigment Content}

To determine the quantitative composition of pigments, cyanobacterial isolates were cultured for 14 days in Allen and Allen $_{0}$ media, as well as in experimental variants with added metals, and then pigment content was analysed. From each variant analysed, $4 \mathrm{~mL}$ of a suspension of 14-day cyanobacterial culture was taken and then centrifuged at 15,000 $\mathrm{g}$ for $7 \mathrm{~min}$, and the supernatant was discarded. Then, $4 \mathrm{~mL}$ of pre-chilled $\left(+4{ }^{\circ} \mathrm{C}\right)$ methanol was added. The sample was homogenized by stirring (Silamat S6, 2 s), shaking $(2000 \times g$, $4 \mathrm{~s})$, and pipetting. Then, the samples were covered with aluminium foil and incubated at $+4{ }^{\circ} \mathrm{C}$ for $20 \mathrm{~min}$ to extract pigments from the cells. Next, the samples were centrifuged at $15,000 \times g,+4{ }^{\circ} \mathrm{C}$ for $7 \mathrm{~min}$ and the precipitate was discarded. The content of pigments (chlorophyll a, carotenoid, and phycocyanin) was determined using a spectrophotometer at wavelengths (A) of 470, 615, 650, 652, 665, and $720 \mathrm{~nm}$ using methanol as a control [37-39].

The concentration of the pigment content was calculated using Equations (1-3):

$$
\begin{aligned}
& \text { Chlorophyll a }\left(\mu \mathrm{g} \mathrm{m}^{-1}\right)=12.9447\left(\mathrm{~A}_{665}-\mathrm{A}_{720}\right) \\
& \text { Carotenoid }\left(\mu \mathrm{g} \mathrm{mL}^{-1}\right)=1000\left(\mathrm{~A}_{470}-\mathrm{A}_{720}\right)-2.86 \\
& \text { Phycocyanin }\left(\mu \mathrm{g} \mathrm{mL}^{-1}\right)=\left(\mathrm{A}_{615}-0.474 \mathrm{~A}_{652}\right) / 5.34
\end{aligned}
$$

\subsection{Statistical Analysis}

The studies were conducted in 3-5 repetitions. The statistical data processing was conducted using the RStudio software (version 1.3.959, R Studio PBC, 2020). An ANOVA was used for the evaluation of significance. When the ANOVA proved a significant 
difference, Tukey's HSD test was performed to compare. Based on Tukey's HSD test, treatments were categorized (into letters in descending gradation). To create graphs on the evaluation of the nitrogenase and photosynthetic activities of cyanobacteria isolated from rice paddies, Microsoft Office Excel 2013 was used. A phylogenetic tree was constructed using the neighbour-joining method in Mega software 6.0 with 1000 bootstrap values [40].

\section{Results}

\subsection{Isolation of Cyanobacteria Axenic Cultures from Rice Fields}

To study the biodiversity of phototrophic microorganisms and isolate nitrogen-fixing cyanobacteria, water, soil, algal mat, and plant samples were collected twice from rice fields at the end of the rice seedling and tillering phases. The study of rice fields in the Kyzylorda region, Republic of Kazakhstan (GeoCoordinate: 43 $54^{\prime} 16^{\prime \prime}$ N 67 $15^{\prime} 04^{\prime \prime}$ E), revealed a rich biodiversity of algoflora consisting of 58 species, forms and varieties of microalgae belonging to 5 phyla, 10 classes, 19 orders, 26 families, and 29 genera. The taxonomic structure of the studied algoflora is as follows: Cyanobacteria-25 (45\%), Bacillariophyta-5 (10\%), Euglenophyta-5 (3\%), Chlorophyta-18 (33\%), and Charophyta-5 (8\%).

At the same time, it must be noted that there is a certain seasonality in the occurrence of the species studied. Thus, if at the end of the rice seedling phase there was a high frequency of occurrence of green algal species of the Chlorophyta and Charophyta phyla, which form a bright green mass on the surface and in the water layer, at the end of the tillering phase, they were replaced by representatives of the Cyanobacteria phylum, especially Microcystis pulverea, Anabaena variabilis, Cylindrospermum sp., Merismopedia elegans, Gloeocapsa minuta, Stranonostoc linkia, Oscillatoria limosa, Spirulina major, Phormidium ambiguum, and Nostoc pruniforme. They are found in the water layer and on the surface, on the leaves and stems of rice and weeds, and on the thallus of dying macroalgae. Representatives of diatoms were more common at the rice seedling phase.

To isolate cyanobacteria, samples of the algal mat were taken towards the end of the rice tillering phase. From the collected water, soil and algal mat samples and 18 enrichment cultures of the dominant species of phototrophic microorganisms were obtained on enriched media. Thirteen cyanobacterial and microalgal isolates, characterised by stable growth under laboratory conditions, were obtained using the serial passage method, nine of which were unialgal cultures.

Since the purpose of this work was to search for and study nitrogen-fixing cyanobacterial strains, our attention was focused only on the filamentous forms of the isolated strains. Thus, five promising isolates, namely SH-12, J-14, J-8, K-31, and J-1, had a filamentous structure and probably belonged to cyanobacteria.

The microscopic examination of these isolates showed that the isolates J-14, K-31, J-8, and J-1 belonged to the order of the Nostocales according to the morphological characteristics and differed from isolate $\mathrm{SH}-12$ in the form and function of cell differentiation. Thus, the single, straight, sometimes slightly curved trichomes of these isolates consisted of bluegreen, spherical or cylindrical, isodiametric vegetative cells, narrowed or not at the ends, with pronounced or slightly pronounced constrictions at stigma sites. A distinctive feature of these isolates was the formation of the terminal and intercalary heterocysts when the medium was exhausted on days 8-15 of cultivation; their size was not significantly different from that of the vegetative cells. In addition, the formation of akinetes was observed in the three isolates, J-14, K-31, and J-8, which were significantly different in size and shape from the vegetative cells, especially isolate J-8. They consisted of cylindrical or oval cells, were 5.1-7.7 $\times$ 2.6-3.4 $\mu \mathrm{m}$ in size, green, light-brown, yellow, granular and bordered on being heterocystous. The formation of akinetes was not observed in isolate J-1. In addition, this isolate was characterised by pronounced false branching of the trichomes, which made the culture appear bushy. The morphological characteristics of the fifth isolate SH-12 resembled those of the genus Oscillatoria, order Oscillatoriales, whose main feature was the non-differentiation of the trichomes. The culture consisted of homocytic, single, straight, 
single-rowed trichomes derived from small, homogeneous, cylindrical vegetative cells lying close together.

A detailed description of each isolate studied is given below (Figure 1):

1. Culture J-14. Filamentous cyanobacteria. The trichomes are single, straight, not narrowed at the ends and have pronounced constrictions at the stigma sites and consist of blue-green spherical vegetative cells (length of 6-8 $\mu \mathrm{m}$, width of 3-5 $\mu \mathrm{m}$ ). The heterocysts are, in most cases, intercalary, solitary, and light-brown. Akinetes are rare, barely noticeably oval, their size does not differ from the size of the cells, and they are characterised by a granular content. They reproduce by hormogonia. Cultural characteristics: Grows well on Allen, Gromov, Bold, and BG-11 media at a temperature of $23-28{ }^{\circ} \mathrm{C}$, with an initial $\mathrm{pH}$ of 7 . At the same time, on a solid medium, prostrate growth is characteristic; on a liquid culture medium, growth is in the form of films both on the surface and at the bottom of the flask. In the old culture or on a medium with nitrogen deficiency, the development of heterocysts and akinetes is observed. According to the systematic position, it is classified as cyanobacteria, class Hormogeneae, order Nostocales, genus Nostoc, Nostoc sp.

2. Culture J-8. Filamentous cyanobacteria. Cells form straight, loose, immobile (weakly motile) trichomes up to $15 \mu \mathrm{m}$ in length, comprising up to 10 cells. The cells are cylindrical, isodiametric, sometimes barrel-shaped, and 1.8-6.8 $\times 2.3-4.3 \mu \mathrm{m}$ in size. The cells in the trichome are light, blue-green, uniform, and not granular. The heterocysts are terminal, unipolar, spherical or elongated, yellow-green, and 3.0-5.9 $\times 2.3-3.2 \mu \mathrm{m}$ in size. The akinetes are mainly cylindrical, oval, large $(5.1-7.7 \times 2.6-3.4 \mu \mathrm{m})$, lightbrown, yellow, granular, and adjacent to the heterocysts. Sometimes there are two akinetes at one end of the trichome. Reproduction is by binary cell division, in one plane only. Cultural characteristics: On a solid medium they form slimy colonies, first green, and then brownish in colour. They grow well at a temperature of $25-30{ }^{\circ} \mathrm{C}$ on Allen and Bold media in the light at an initial $\mathrm{pH}$ of 7 . Old cultures (10-15 days of cultivation) contain both heterocysts and akinetes. Culture J-8 exhibited several morpho-characteristics identical to Cylindrospermum badium [41], including similar size dimensions of trichomes, vegetative cell, heterocysts, and akinete, and a flattened exospore. Therefore, the isolate J-8, after preliminary morphological identification, was assigned to cyanobacteria, class Hormogeneae, order Nostocales, genus Cylindrospermum, and species Cylindrospermum badium.

3. Culture K-31. The cells are cylindrical, barrel-shaped or spherical, pale- or lightblue- or olive-green, with gas bubbles (vacuoles) or without, but sometimes with granular contents. The terminal cells are slightly elongated, not vacuolated. The heterocysts are intercalary, solitary, spaced apart, oval, sometimes spherical, and usually slightly larger than the vegetative cells. The development of heterocysts was observed when the medium was exhausted (on the 8-15th day of cultivation). The akinetes are spherical, solitary, and located in the middle between two heterocysts. This cyanobacterium reproduces by hormogonia. Cultural characteristics: On solid culture medium, they form mucilaginous colonies, on liquid culture medium, they precipitate mucilaginous amorphous tangles, and the walls of the flasks are fouled by the culture. They were isolated on Allen's culture medium and grow well on Bold's, Chu-10, and BG -11 media. The development of heterocysts was observed when the medium was emptied at 8-15 days of cultivation. Optimal growth on this medium was observed at a temperature of $25-28^{\circ} \mathrm{C}[42,43]$. Morphological identification of the isolate shows that the isolate belongs to cyanobacteria, class Hormogeneae, order Nostocales, family Nostocaceae, genus Trichormus, species Trichormus variabilis.

4. Culture J-1. Filamentous cyanobacteria. The cells formed straight, sometimes slightly curved, immobile trichomes up to $10-15 \mu \mathrm{m}$ in length. At the same time, bushiness (bushy growth) is observed in some places due to the false branching of the trichomes, which often occurs at the sites of heterocyst formation. The cells in the trichomes are often cylindrical, isodiametric, and 1.3-3.2 $\mu \mathrm{m}$ in size. The cells in the trichome are 
light, green, uniform, and non-granular. The heterocysts are intercalary, spherical or elongated, yellow-green, and 3-3.2 $\times-5.9 \mu \mathrm{m}$ in size. The presence of akinetes was not observed. Reproduction is by binary cell division, only in one plane. Cultural characteristics: Yellow-green colonies form on a solid medium. They grow well at a temperature of $25-30{ }^{\circ} \mathrm{C}$ on BG-11, Allen, and Bold media in the light, at an initial $\mathrm{pH}$ of 7 . According to taxonomic affiliation, they are assigned to cyanobacteria, class Hormogeneae, order Nostocales, family Scytonemataceae, genus Tolypothrix, and species Tolypothrix sp. [44].

5. Culture SH-12. A filamentous cyanobacterium with a mucilaginous sheath. No active movement of the trichomes was observed, but some rocking of the trichome tips was. The width of the cell is $2.6-5 \mu \mathrm{m}$, i.e., it is two- to three-fold shorter than the length. They reproduce by binary cell division and in one plane only. Cultural characteristics: On a liquid medium, the suspension is blue-green in mass, slightly mucous-like, and precipitates into an amorphous precipitate that is easily stirred up. The strain develops regardless of the season and remains axenic during storage. This cyanobacterium is isolated on Gromov's culture medium and grows well on Allen's and BG-11 media. Blue-green trichome balls form on the surface of Gromov's agar medium. Optimal cultivation conditions are on Gromov's medium at an incubation temperature of 25-28 ${ }^{\circ} \mathrm{C}$, medium $\mathrm{pH}$ was 7.5-8. Based on the morphological characteristics, which are congruent with the description reported in previous literature, the isolated strain was identified as Oscillatoria brevis $[45,46]$. According to the systematic position, they belong to the cyanobacteria, class Hormogeneae, order Oscillatoriales, genus Oscillatoria, and species Oscillatoria brevis.
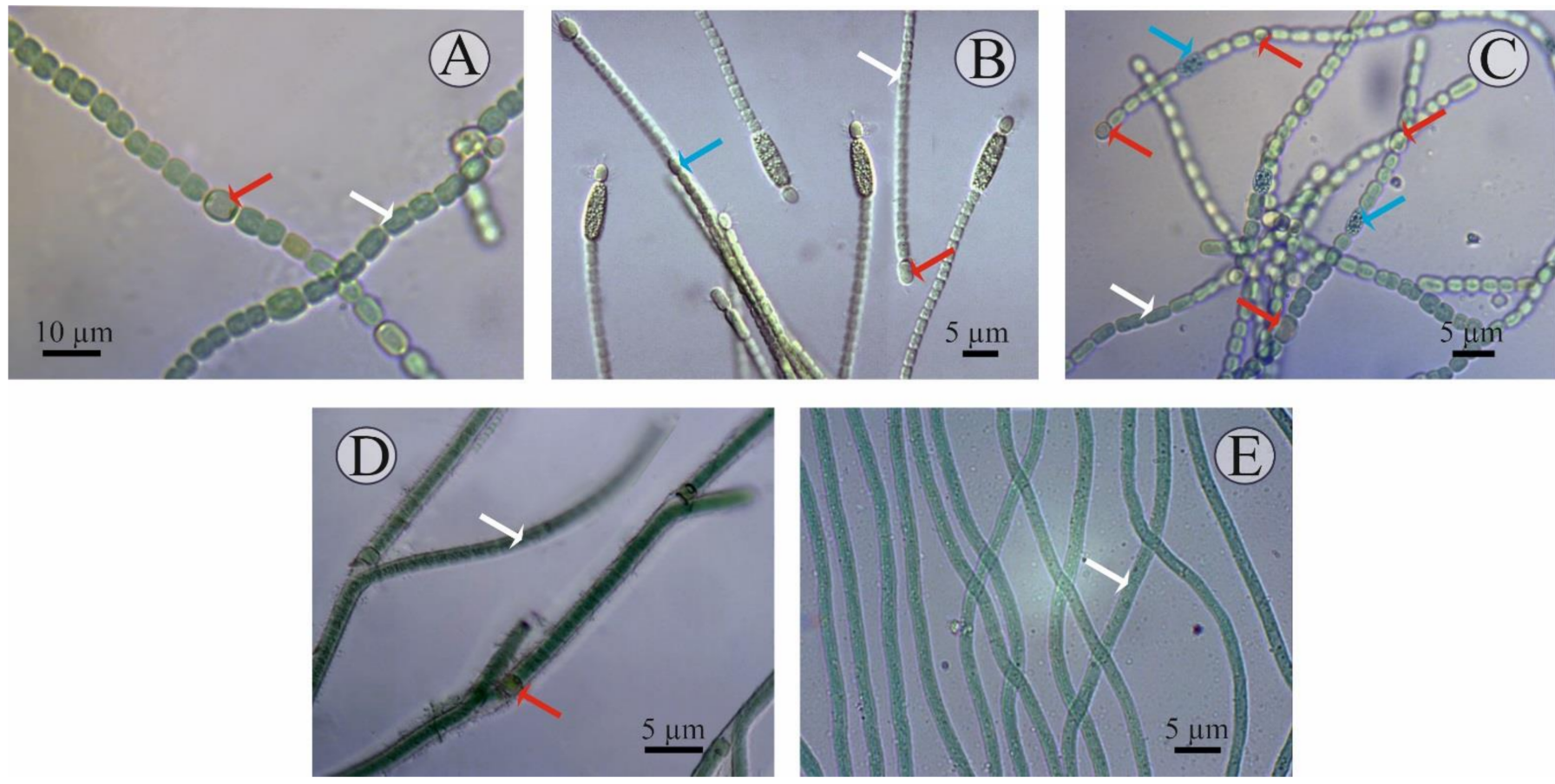

Figure 1. Microscopic images of the cyanobacterial isolates: (A) Nostoc J-14, (B) Cylindrospermum J-8, (C) Trichormus K-31, (D) Tolypothrix J-1, and (E) Oscillatoria SH-12. Formation of the different cell types are marked in arrow colours: white—vegetative cells; red-heterocysts; blue—akinetes.

The isolated pure cultures are stored in the biotechnology laboratory of the Department of Biotechnology of Al-Farabi Kazakh National University in the Collection of microalgae and cyanobacteria CCMKazNU (Culture Collection of microalgae, Al-Farabi Kazakh National University). 


\subsection{Genetic Identification of Isolated Strains and Phylogenetic Tree Construction}

For the molecular identification of the isolated strains, DNA fragments of different lengths were obtained. These DNA fragments were amplified with 16 rRNA universal primers, and similar strands were identified in the NCBI BLAST online database.

Based on the data obtained, eight entries in the chain with high similarity were selected, and several alignments were performed using the MUSCLE program. The phylogenetic tree was constructed using MEGA 6 software based on the evolutionary distance calculated using the neighbour-joining method based on the Kimura-2-Parameter algorithm. The statistical analysis of the tree topology was carried out using a loading analysis of 1000 repeated samples [47].

The phylogenetic tree consists of four main clusters and one group, each represented mainly by different species of Cylindrospermum, Anabaena, Tolypothrix, and Oscillatoria. Chlorella antarctica strain CCAP 211/45 (KU291887.1) was used as an outgroup.

Figure 2 shows the phylogenetic relationships of the neighbouring strains and the topology of the tree, which is the basis for the sequential comparison of the taxa.

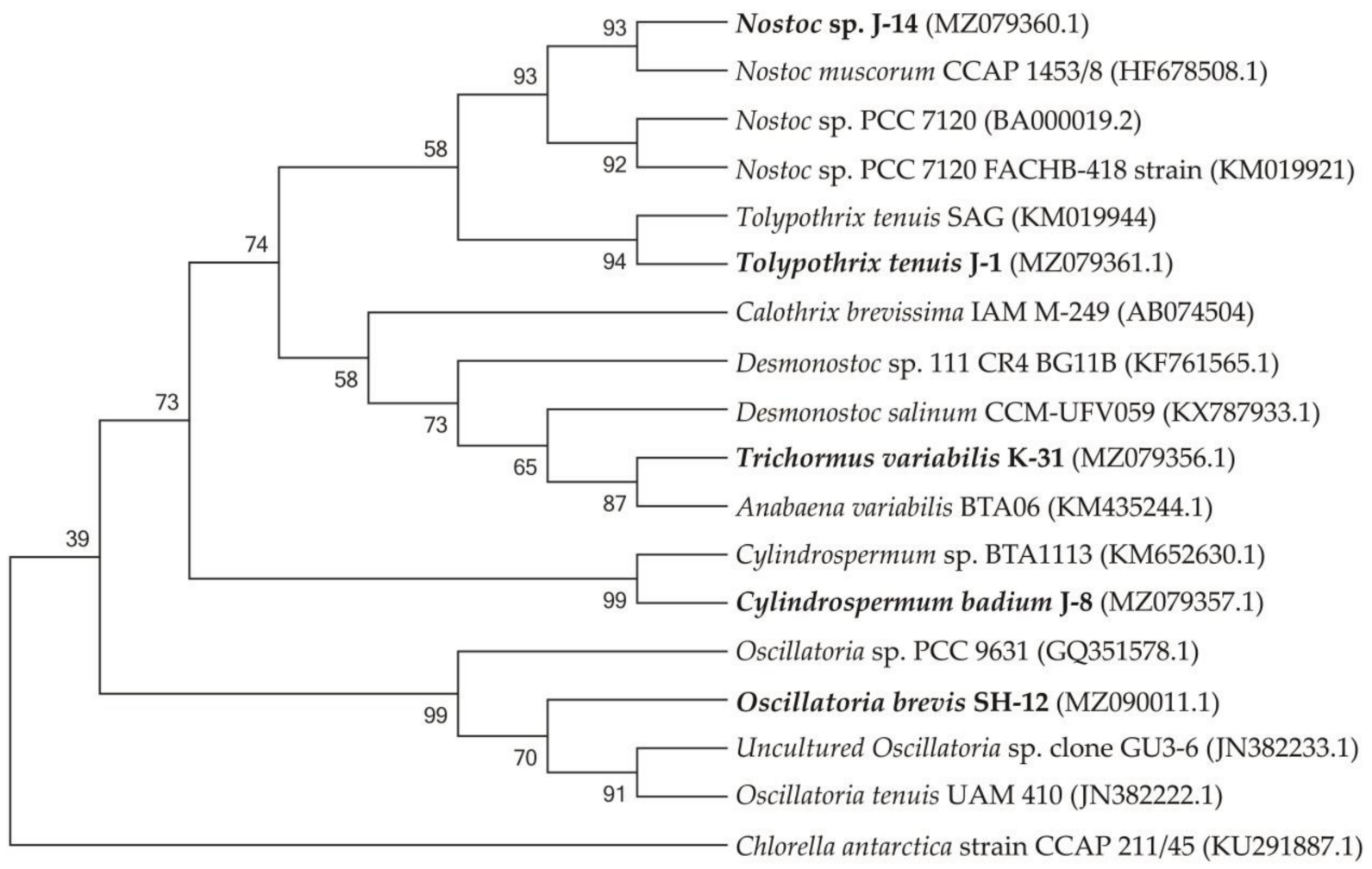

Figure 2. Isolated cyanobacterial strains and phylogenetic tree of neighbouring species.

The SH-12 strain (MH341423) was 99.76\% close to Oscillatoria tenuis (JN382222.1) and Uncultured Oscillatoria sp. clone GU3-6 (JN382233.1). The phylogram showed that strain J-14 belongs to Nostoc genus, similar to Nostoc muscorum with accession number HF678508.1 $(\mathrm{sc} .=2326$; sim. $=99.38 \%$ ), and Nostoc sp. with accession number KM019921.1 (sc. = 2298, sim. $=99.45 \%$ ). Strain J-1 showed 99.33\% affinity to Tolypothrix tenuis (KM019944.1) and 99.41\% similarity to Scytonema mirabile (KM019943.1) showed. 1354 nucleotide sequences were obtained with a combination of two additional primers. The J-8 chains were identified with universal primers $27 \mathrm{f}$ and $1492 \mathrm{r}$ and showed a close affinity with Cylindrospermum sp. BTA1113 (KM652ß630.1) (sc. = 785, sim. = 94.36\%). The affinity of other neighbouring species was $90.47 \%$, such as Desmonostoc salinum (sc. = 702), Desmonostoc sp. $(90.36 \%)$. The results showed that strain K-31 was closely related to Nostoc sp. SAG 34.92, Anabaena variabilis BTA with $96.62 \%$ and Trichormus variabilis $94.21 \%$ similarity. Despite the fact that the percentage of similarity with Anabaena variabilis is greater, according to morphological 
features (the location of akinetes in relation to heterocysts), strain K-31 is assigned to the genus Trihormus. The genus Trihormus was isolated from the genus Anabaena within the subfamily Nostocoidae. According to the information available in the literature, the genus Trichormus includes $A$. variabilis, $A$. azollae Strasb., A. doliolum Bharadw, and a number of other species, and thus the names $A$. variabilis and T. variabilis (Kütz.) Kom. and Anagn. at one time were considered synonyms [48]. However, despite this, the genus Trichormus is characterized by the formation of akinetes from vegetative cells in the middle, between two heterocysts, while in Anabaena cells, akinetes are formed nearby with heterocysts, and their growth is directed away from the heterocysts. In the K-31 strain, akinetes were located in the middle between two heterocysts at an equal distance; therefore, this strain was assigned to the genus Trichomus. According to the research results, a genetic analysis of five cyanobacterial cultures was performed based on phylogenetic analysis, their close groups were identified, and phylogenetic trees were formed. The resulting nucleotide chains were uploaded to the GenBank database (NCBI) and accession numbers were assigned. Through phylogenetic and morphological analyses, the isolated new cyanobacterial isolates were identified as follows: Trichormus variabilis K-31 (MZ079356), Cylindrospermum badium J-8 (MZ079357), Nostoc sp. J-14 (MZ079360), Oscillatoria brevis SH-12 (MZ090011), and Tolypothrix tenuis J-1 (MZ079361).

\subsection{Investigation of the Productivity of Isolated Cyanobacterial Strains on a Nitrogen-Free Medium}

The next step was to investigate the ability of the isolated cyanobacteria to grow on a nitrogen-free nutrient medium $\left(\right.$ Allen $_{0}$ ) while determining the formation of heterocysts on the filament and the nitrogenase activity of the strains under these conditions. For this purpose, the cultures of four heterocystous cyanobacterial strains were grown on the nutrient medium Allen, and the number of heterocystous (HC) and vegetative cells (VC) within a filament, as well as the growth rate coefficient of the cultured cyanobacteria, were recorded daily. After 14 days, the biomass of the cyanobacteria was separated from the culture fluid and dried and, thereafter, the yield of dry biomass was determined. The results obtained are summarised in Table 1.

Table 1. The productivity results of isolated microalgal strains on a nitrogen-free medium $\left(\right.$ Allen $\left._{0}\right)$. The data are presented as mean $+/-\mathrm{SE}(n=3), p<0.05$.

\begin{tabular}{ccc}
\hline Strain & Growth Coefficient, $\boldsymbol{\mu}$ (per Day) & DW, $\mathbf{g ~ L}^{-\mathbf{1}}$ \\
\hline Trichormus variabilis K-31 & $0.28 \pm 0.02$ & $1.06 \pm 0.09$ \\
Nostoc sp. J-14 & $0.27 \pm 0.02$ & $1.01 \pm 0.09$ \\
Cylindrospermum badium J-8 & $0.19 \pm 0.02$ & $0.87 \pm 0.08$ \\
Tolypothrix tenuis J-1 & $0.24 \pm 0.02$ & $0.91 \pm 0.07$ \\
\hline
\end{tabular}

In general, it can be stated that all strains examined were able to grow on a nitrogenfree medium. However, compared to the control, a significant prolongation of the lag phase of culture growth on a nitrogen-free medium was observed. In the course of cultivation, the growth rate coefficient of the examined strains reached different values, whereby the most active growth was observed in the representatives of the order Nostocales - the strains Trihormus variabilis K-31 and Nostoc sp. J-14-whose yield of dry biomass at the end of the experiment was $1.06 \pm 0.09$ and $1.01 \pm 0.09 \mathrm{~g} \mathrm{~L}^{-1}$, respectively.

The results obtained indicate a significant difference in the productivity of the representatives of the order Nostocales on a nitrogen-free medium: the highest productivity among the strains studied was observed in Trihormus variabilis K-31 and Nostoc sp. J-14. The ability to grow on a medium without nitrogen in all the cultures studied already indicates the presence of nitrogen-fixing activity in isolated cultures of cyanobacteria. The registration of the number of heterocysts showed that an increase in the number of heterocysts was observed in all cultures on a nitrogen-free medium, despite a slight decrease in the growth rate. After 9 days of culturing the strains on a nitrogen-free medium, it was found that 
there were no significant differences between the cultures grown on both Allen nutrient medium and Allen $_{0}$ nitrogen-free medium. In the experiment in Allen nutrient medium, three strains were characterised by the active formation of heterocysts. It was found that the cells of Trihormus variabilis K-31 formed 5 HC/filament, Nostoc sp. J-14, 3 HC/filament, and the strains Cylindrospermum badium J-8 and Tolypothrix tenuis J-1 released a maximum of $4 \mathrm{HC} /$ filament. These values are about two- to three-fold higher than in the control, where the number of heterocysts correlates positively with cell density or biomass (Figure 3).

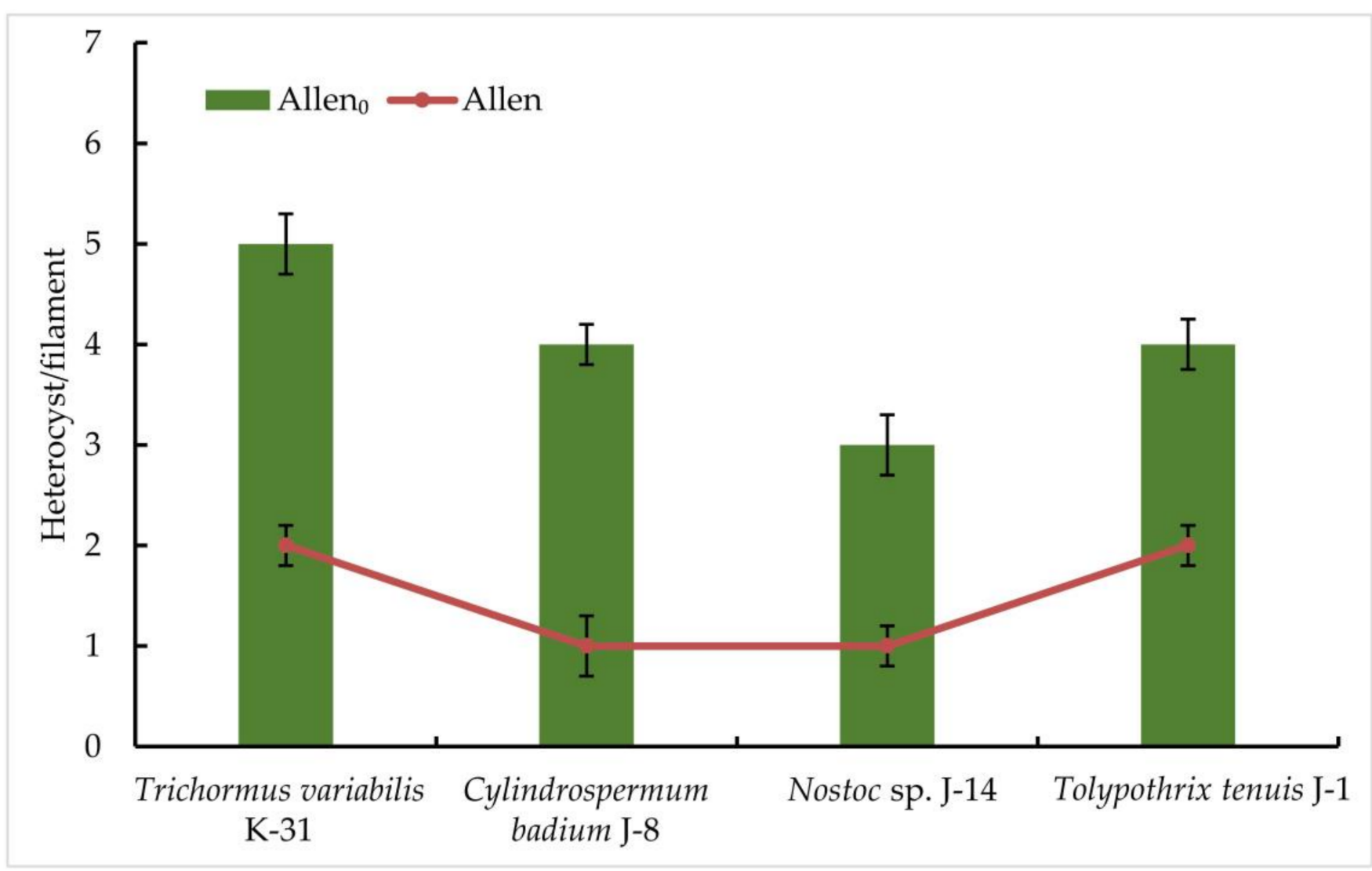

Figure 3. The frequency of heterocyst formation during nitrogen starvation in isolated cyanobacterial strains. The species were grown in the Allen medium for 14 days. The biomass was collected and transferred to the Allen 0 medium. Then, heterocyst formation was studied under a light microscope. Different letters on the bar and line chart indicate a significant difference at $p<0.05$.

Then, five isolated cyanobacterial strains were tested for nitrogenase activity, including Oscillatoria brevis SH-12. A cyanobacterial strain that does not form heterocysts (Synechocystis sp. PCC 6803) was used as a control. The results of gas chromatography showed that all strains of nitrogen-fixing cyanobacteria exhibited nitrogen activity in the acetylene medium. However, their ability to reduce acetylene to ethylene was found to vary. According to the results, among the species studied, the strain Oscillatoria brevis SH-12 showed no nitrogenase activity, as expected, while the strain Trichormus variabilis $\mathrm{K}-31$ had the highest ethylene content $\left(3.57 \pm 0.26 \mathrm{nmol}\right.$ ethylene $\left.\mathrm{mg}^{-1} \mathrm{DW} \mathrm{h}^{-1}\right)$. In addition, the strains Nostoc sp. J-14 (2.82 $\pm 0.07 \mathrm{nmol}$ ethylene $\left.\mathrm{mg}^{-1} \mathrm{DW} \mathrm{h}^{-1}\right)$ and Tolypothrix tenuis $\mathrm{J}-1\left(2.22 \pm 0.06 \mathrm{nmol}\right.$ ethylene $\left.\mathrm{mg}^{-1} \mathrm{DW} \mathrm{h}^{-1}\right)$ showed good results. In the strain Cylindrospermum badium J-8, this indicator was $1.36 \pm 0.05 \mathrm{nmol}$ ethylene $\mathrm{mg}^{-1} \mathrm{DW} \mathrm{h}^{-1}$ (Figure 4). 


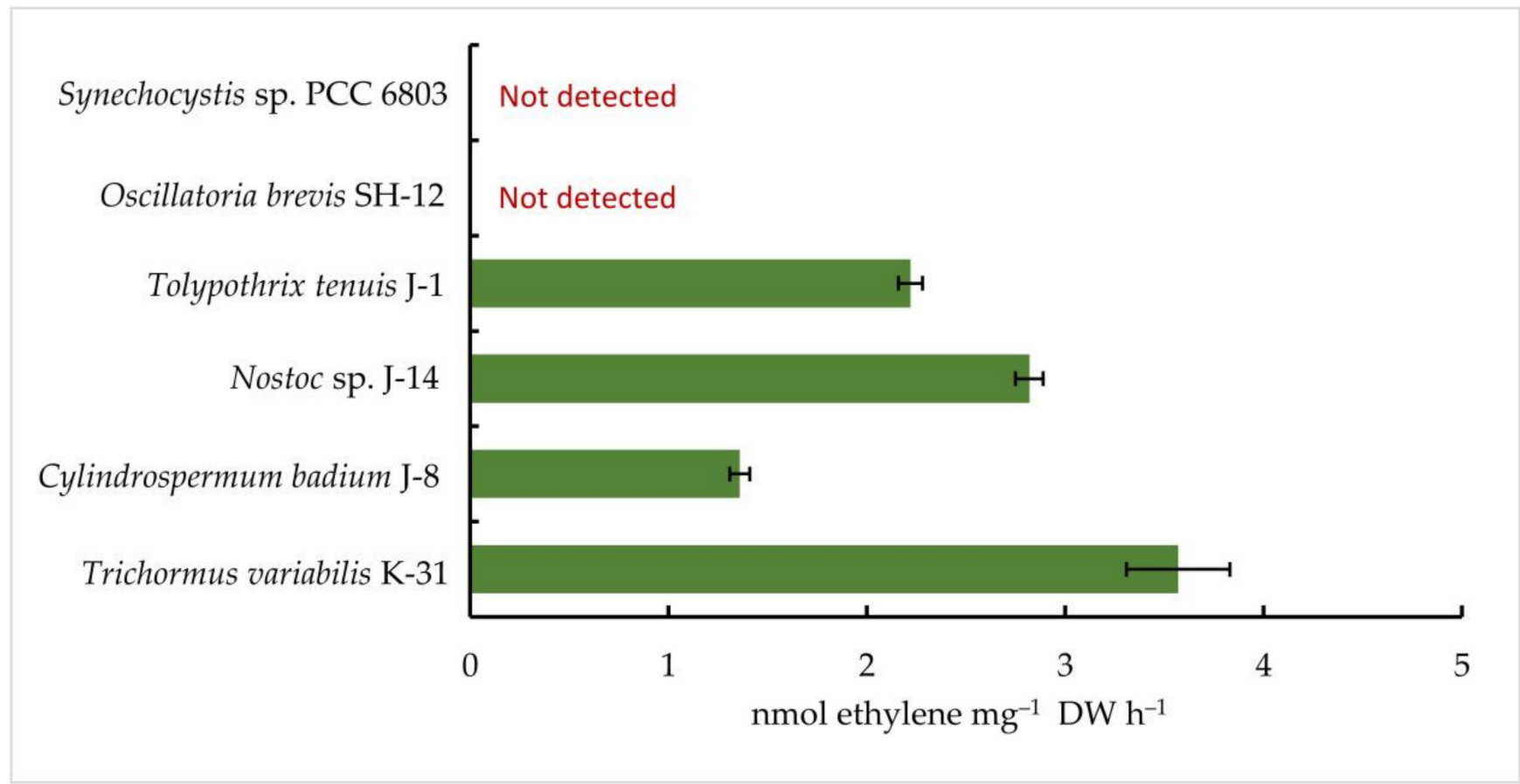

Figure 4. Nitrogenase activity of isolated cyanobacterial strains. The cells were cultured until the beginning of the stationary phase of the cells. Next, collected biomass was transferred to the Allen 0 nitrogen-free medium. After $24 \mathrm{~h}$, the concentration of ethylene was measured. The data are presented as mean $+/-\operatorname{SE}(n=3)$. Different letters on the bar indicate a significant difference at $p<0.05$.

Thus, based on the experiments, it was found that four out of five isolated cyanobacterial strains have some ability to fix nitrogen. The best results were obtained for representatives of the order Nostocales. The strains Trihormus variabilis K-31 and Nostoc sp. J-14 had the highest nitrogen fixation activity.

\subsection{Influence of Mo and Fe on Photosynthetic and Nitrogenase Activities of Isolated Cyanobacterial Strains}

The effect of the investigated biogenic metals on the photosynthetic activity of the isolated strains was assessed using some fluorescence parameters and the biomass pigment composition. Using an M-PEA-2 fluorimeter, which allows for the simultaneous measurement of induction fluorescence curves and the redox conversions of photosystem components in the microsecond range, the effect of different concentrations of molybdenum (Mo) and iron $(\mathrm{Fe})$ on the maximum quantum yield of PSII of the primary photochemical reactions $F v / F m\left(\varphi_{\mathrm{Po}}\right)$ was investigated as a first step. This indicator was determined at the time of the peak of nitrogenase activity in a nitrogen-free medium (i.e., according to preliminary data, this is about $24 \mathrm{~h}$ ).

According to the data obtained, the maximum quantum yield of PSII of the primary photochemical reactions $\mathrm{Fv} / \mathrm{Fm}$ correlated positively with an increase in the Fe concentration in the medium in both strains. In Trihormus variabilis K-31, a linear increase in the $\mathrm{Fv} / \mathrm{Fm}$ parameter was observed with increasing Fe concentration, from values of 0.31 to 0.58 at 1 to $10 \mu \mathrm{mol} \mathrm{Fe} \mathrm{concentrations.} \mathrm{With} \mathrm{a} \mathrm{further} \mathrm{increase} \mathrm{in} \mathrm{the} \mathrm{metal} \mathrm{concentration} \mathrm{to}$ $15 \mu \mathrm{mol}$, a sharp decrease in the Fv/Fm value to 0.28 is observed (Figure 5).

The strain Nostoc sp. J-14 showed a similar pattern and differed from Trichomus variabilis K-31 with lower values. In general, a clear relationship between Fe concentration and PSII photochemical quantum yield was also observed. Thus, $\mathrm{Fv} / \mathrm{Fm}$ values for Nostoc sp. J-14 were $50 \%$ lower under conditions of low metal concentration $(1 \mu \mathrm{mol})$ and were 0.26 compared to conditions of medium enrichment with $10 \mu \mathrm{mol} \mathrm{Fe} \mathrm{(0.50).}$ 


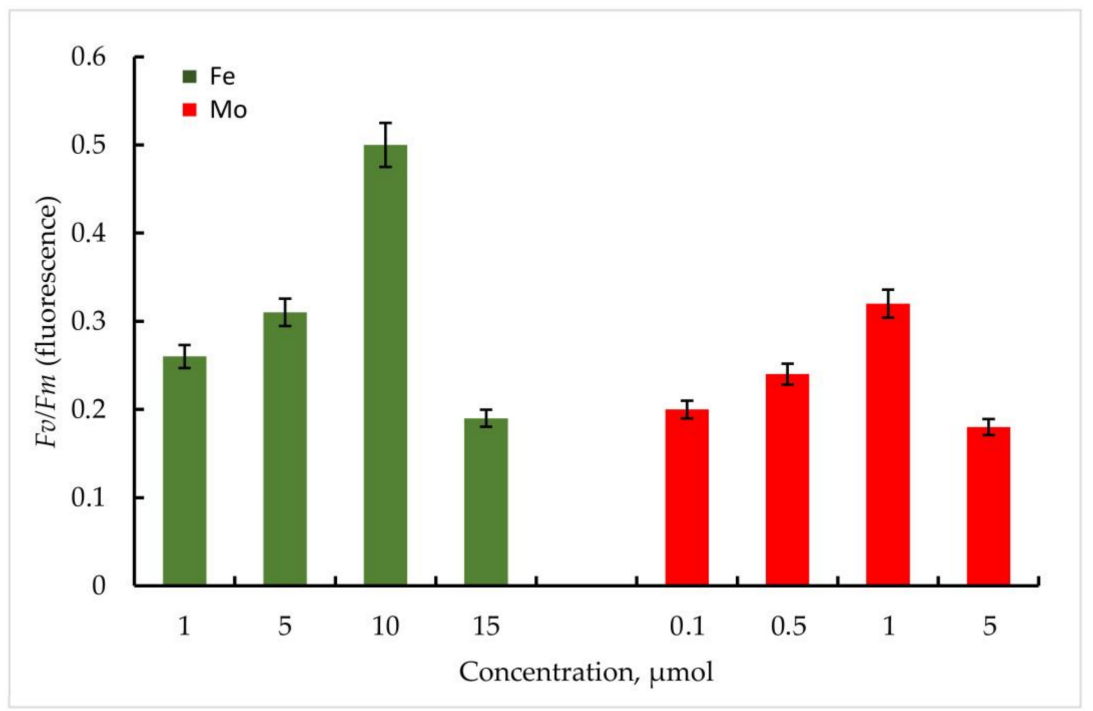

Figure 5. Maximum quantum yield of PSII $(F v / F m)$ of primary photochemical reactions at different Mo and Fe concentrations for Trihormus variabilis K-31. The culture was grown on Allen medium for 7 days. The obtained biomass was transferred to the medium containing different concentrations of Fe $(1,5,10$, and $15 \mu \mathrm{mol})$ and Mo $(0.1,0.5,1$, and $5 \mu \mathrm{mol})$ metals. Then, the ratio of Fv/Fm values was measured. The data are presented as mean $+/-$ SE $(n=4)$. Different letters on the bar indicate a significant difference at $p<0.05$.

It should be noted that in the experiments with Mo, despite its stimulating effect on nitrogenase activity in cyanobacteria, the parameters of the maximum quantum yield of PSII of the primary photochemical reactions Fv/Fm were significantly lower compared to Fe.

Thus, within the investigated Mo concentrations, the maximum value of the Fv/Fm parameter was found at a Mo concentration of $1 \mu \mathrm{mol}$. For the strain Trihormus variabilis $\mathrm{K}-31$, this value was 0.42 , for Nostoc sp. J-14, 0.32 . The ratio of $\mathrm{Fv} / \mathrm{Fm}$ values for both strains at different Mo and Fe concentrations in comparison is shown in Figure 6.

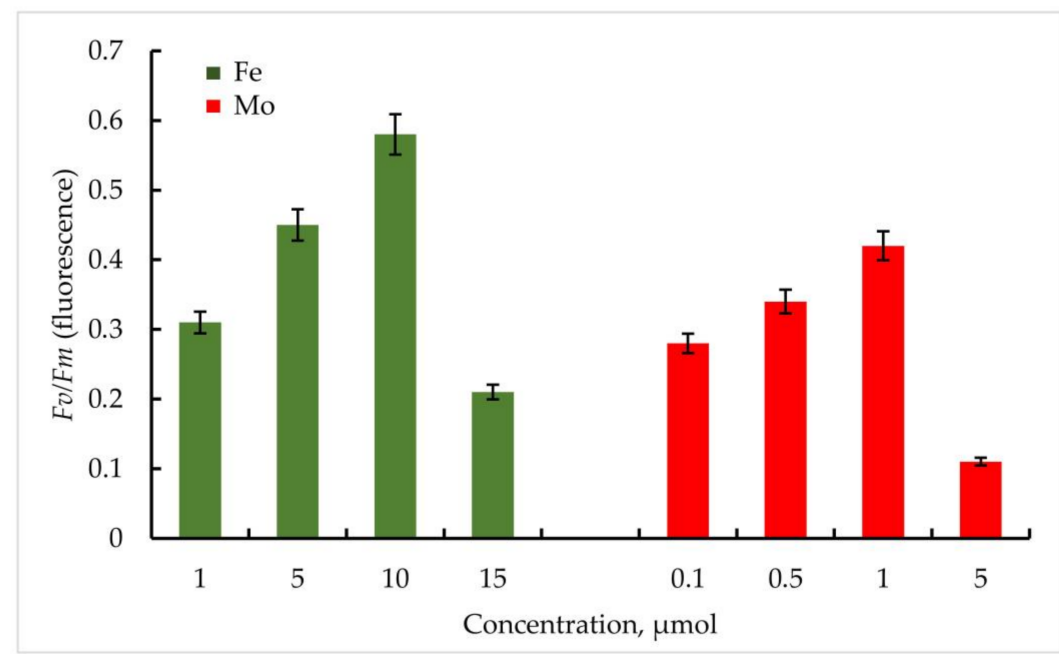

Figure 6. PSII maximum quantum yield $F v / F m\left(\varphi_{\mathrm{Po}}\right)$ of primary photochemical reactions at different Mo and Fe concentrations for Nostoc sp. J-14. The culture was grown on Allen medium for 7 days. The obtained biomass was transferred to the medium containing different concentrations of Fe ( 1 , $5,10$, and $15 \mu \mathrm{mol})$ and Mo $(0.1,0.5,1$, and $5 \mu \mathrm{mol})$ metals. Then, the ratio of $\mathrm{Fv} / \mathrm{Fm}$ values was measured. The data are presented as mean $+/-\operatorname{SE}(n=4)$. Different letters on the bar indicate a significant difference at $p<0.05$. 
To investigate pigment composition, the strains were cultured for 14 days in Allen medium without nitrogen, after which the resulting biomass was analysed for chlorophyll $a$, carotenoid, and phycocyanin content. Metal concentrations were selected based on preliminary studies. Since the yield of dry biomass was different in the different variants of the experiment, the content of pigments was recalculated for $1 \mathrm{mg} \mathrm{g}^{-1} \mathrm{DW}$. The results obtained are summarised in Table 2.

Table 2. Pigment composition of cyanobacterial isolates under the influence of the metal. Different letters within one pigment indicate a significant difference at $p<0.05$.

\begin{tabular}{|c|c|c|c|c|c|}
\hline \multirow{2}{*}{ Strain } & \multirow{2}{*}{ Metal } & \multirow{2}{*}{$\begin{array}{c}\text { Concentration, } \\
\mu \mathrm{mol}\end{array}$} & \multicolumn{3}{|c|}{ Pigment Content, $\mathrm{mg} \mathrm{g}^{-1} \mathrm{DW}$} \\
\hline & & & Chlorophyll $a$ & Carotenoid & Phycocyanin \\
\hline \multirow{4}{*}{$\begin{array}{c}\text { Trichormus } \\
\text { variabilis K-31 }\end{array}$} & Mo & 1 & $0.38 \pm 0.024$ & $0.18 \pm 0.016$ & $0.19 \pm 0.011$ \\
\hline & $\mathrm{Fe}$ & 10 & $0.46 \pm 0.018$ & $0.23 \pm 0.014$ & $0.58 \pm 0.018$ \\
\hline & Control A ${ }^{1}$ & $\mathrm{NA}^{3}$ & $0.29 \pm 0.015$ & $0.14 \pm 0.012$ & $0.15 \pm 0.011$ \\
\hline & Control B ${ }^{2}$ & NA & $0.45 \pm 0.014$ & $0.22 \pm 0.011$ & $0.18 \pm 0.012$ \\
\hline \multirow{4}{*}{ Nostoc sp. J-14 } & Mo & 1 & $0.31 \pm 0.021$ & $0.23 \pm 0.023$ & $0.13 \pm 0.013$ \\
\hline & $\mathrm{Fe}$ & 10 & $0.37 \pm 0.019$ & $0.25 \pm 0.016$ & $0.47 \pm 0.015$ \\
\hline & Control A ${ }^{1}$ & NA & $0.31 \pm 0.011$ & $0.22 \pm 0.011$ & $0.11 \pm 0.012$ \\
\hline & Control B ${ }^{2}$ & NA & $0.35 \pm 0.011$ & $0.24 \pm 0.019$ & $0.21 \pm 0.015$ \\
\hline
\end{tabular}

The obtained results show that the metals concentrations optimal for nitrogen fixa-tion affect the process of photosynthesis in different ways, especially the pigments content. As expected, the addition of Fe to the medium compared to Mo increases the photosynthetic activity of both cyanobacterial strains under nitrogen deficiency. Thus, considering Trichomus variabilis K-31, the content of chlorophyll a in control A (medium without nitrogen) was $0.29 \pm 0.015 \mathrm{mg} \mathrm{g}^{-1} \mathrm{DW}$ being significantly higher in the presence of $10 \mu \mathrm{mol}$ Fe $\left(0.46 \pm 0.018 \mathrm{mg} \mathrm{g}^{-1} \mathrm{DW}\right)$. In control B (Allen medium with standard composition) the content of chlorophyll a was $0.45 \pm 0.014 \mathrm{mg} \mathrm{g}^{-1}$. The content of carotenoid in the presence of Fe was amounted to $0.23 \mathrm{mg} \mathrm{g}^{-1}$, which corresponded to control B-0.22 $\pm 0.011 \mathrm{mg} \mathrm{g}^{-1}$, while this indicator on the medium without nitrogen was $0.14 \pm 0.012 \mathrm{mg} \mathrm{g}^{-1}$. A slightly different picture was obtained for phycocyanin. The best accumulation of phycocyanin was observed in the presence of Fe $\left(0.58 \pm 0.018 \mathrm{mg} \mathrm{g}^{-1}\right)$ compared to the controls and the Mo variant.

The influence of the selected Mo and Fe concentrations on the nitrogenase activity of Trichormus variabilis K-31 and Nostoc sp. J-14 was determined after 1, 2, 4, 8, 24, and 32 h.

The results obtained proved the stimulating effect of the investigated metals on the nitrogenase activity of the cyanobacteria.

Thus, in Trichomus variabilis K-31, when exposed to $1 \mu \mathrm{mol} \mathrm{Mo}$, the maximum accumulation of $\mathrm{C}_{2} \mathrm{H}_{4}$ was observed after $24 \mathrm{~h}$ and $5.2 \pm 0.6 \mathrm{nmol}$ ethylene $\mathrm{mg}^{-1} \mathrm{DW} \mathrm{h}^{-1}$, which is $48 \%$ higher than in the control (Figure 7). According to the data obtained, nitrogenase activity was high up to $24 \mathrm{~h}$, and the amount of ethylene decreased in the following hours. This, in turn, is closely related to a decrease in glycogen stores. As you know, nitrogen fixation is an energy-rich process in which the nitrogenase releases three identical products simultaneously. Sufficiently good results were obtained with Fe addition, and the maximum oxidation of $\mathrm{C}_{2} \mathrm{H}_{4}$ showed $4.2 \pm 0.8 \mathrm{nmol}$ ethylene $\mathrm{mg}^{-1} \mathrm{DW} \mathrm{h}^{-1}$ at a concentration of $5 \mu \mathrm{mol}$ after $24 \mathrm{~h}$ of the experiment.

It should be noted that nitrogenase activity was significantly lower in the control. The content of ethylene reached $1.6 \pm 0.5 \mathrm{nmol}$ ethylene $\mathrm{mg}^{-1} \mathrm{DW} \mathrm{h}^{-1}$ in the first hours of the experiment, which increased to a maximum point of $3.6 \pm 0.5 \mathrm{nmol}$ ethylene $\mathrm{mg}^{-1} \mathrm{DW} \mathrm{h}^{-1}$ after $24 \mathrm{~h}$ of the experiment.

In the experiment with the strain Nostoc sp. J-14, the isolate also showed ethylene activity when exposed to the investigated metals; however, the oxidation of $\mathrm{C}_{2} \mathrm{H}_{4}$ was comparatively lower than that of Trichormus variabilis K-31. At $1 \mu \mathrm{mol} \mathrm{Mo}, 1.5 \pm 0.2 \mathrm{nmol}$ ethylene $\mathrm{mg}^{-1} \mathrm{DW} \mathrm{h}^{-1} \mathrm{C}_{2} \mathrm{H}_{4}$ was measured after $1 \mathrm{~h}$. A high rate of oxidation of $\mathrm{C}_{2} \mathrm{H}_{2}$ to $\mathrm{C}_{2} \mathrm{H}_{4}$ was observed after $24 \mathrm{~h}\left(4.4 \pm 2.6 \mathrm{nmol}\right.$ ethylene $\left.\mathrm{mg}^{-1} \mathrm{DW} \mathrm{h}^{-1}\right)$, which is $57 \%$ more than in the control. Under the influence of $\mathrm{Fe}$, the maximum oxidation of $\mathrm{C}_{2} \mathrm{H}_{4}$ 
at a concentration of $10 \mu \mathrm{mol}$ after $24 \mathrm{~h}$ of the experiment was $3.8 \pm 0.7 \mathrm{nmol}$ ethylene $\mathrm{mg}^{-1} \mathrm{DW} \mathrm{h}^{-1}$ (35\% more than in the control), in the following hours, a noticeable decrease in this indicator was observed (Figure 8).

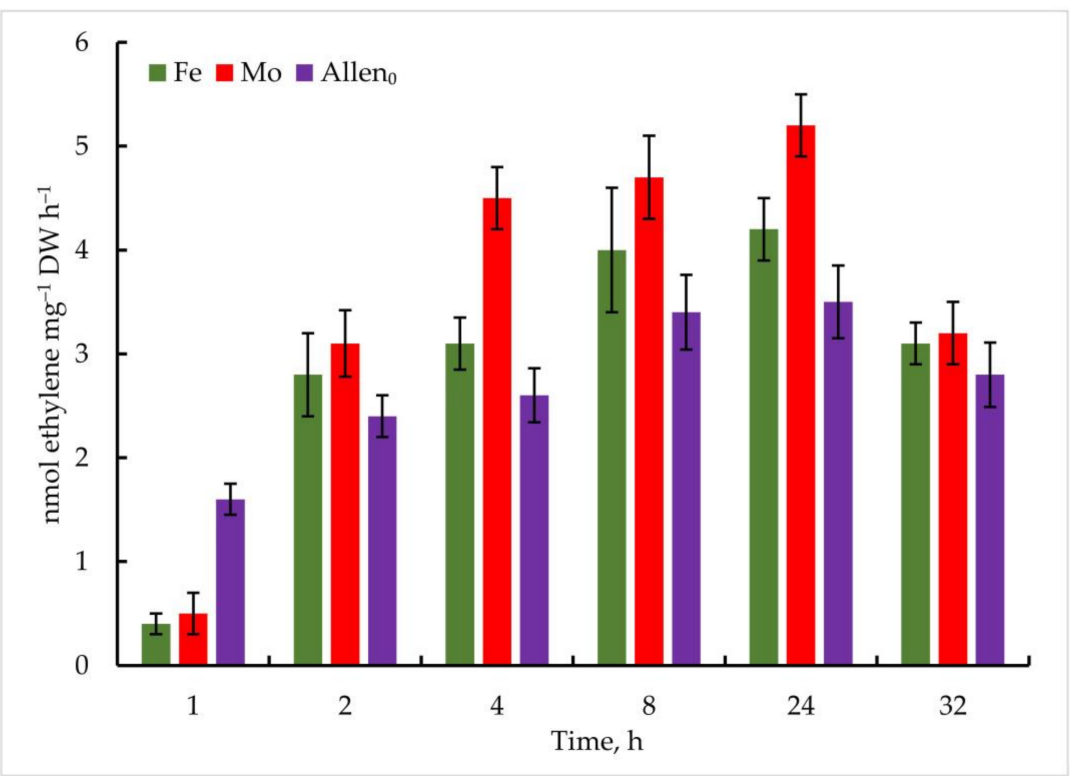

Figure 7. Metal-induced increase in nitrogenase activity in Trichormus variabilis K-31 cells. The culture was grown on Allen medium for 7 days. Then, the cells were transferred to media containing Mo $(1 \mu \mathrm{mol})$ and Fe $(10 \mu \mathrm{mol})$ at time 0 . Acetylene yield was measured at 1, 2, 4, 8, 24, and $32 \mathrm{~h}$ after the addition of the Mo and Fe containing salts. The data are presented as mean $+/-\mathrm{SE}(n=5)$. Different letters on the bar indicate a significant difference at $p<0.05$.

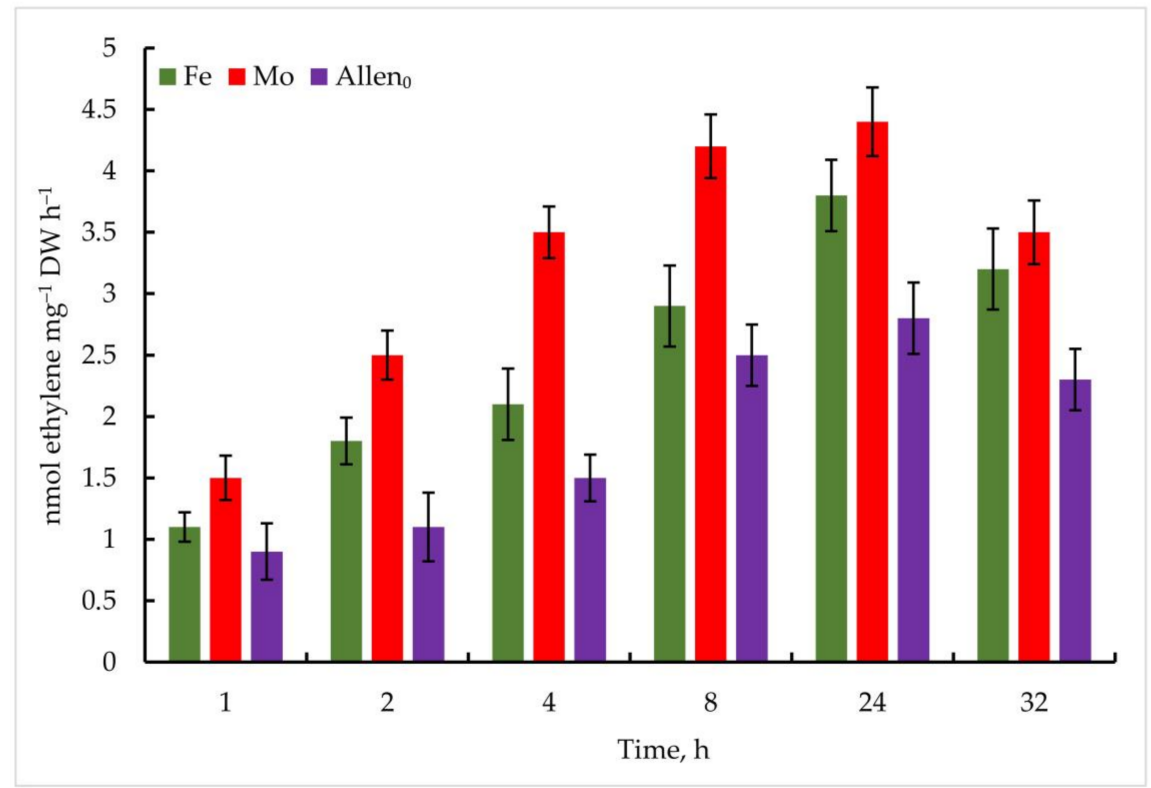

Figure 8. Metal-induced increase in nitrogenase activity in Nostoc sp. J-14 cells. The culture was grown on Allen medium for 7 days. Then, the cells were transferred to media containing Mo $(1 \mu \mathrm{mol})$ and $\mathrm{Fe}(10 \mu \mathrm{mol})$ at time 0 . Acetylene yield was measured at 1, 2, 4, 8, 24, and $32 \mathrm{~h}$ after the addition of the Mo and Fe containing salts. The data are presented as mean $+/-\mathrm{SE}(n=5)$. Different letters on the bar indicate a significant difference at $p<0.05$.

According to the results obtained, it was found that the examined concentrations of each metal have a stimulating effect on nitrogenase activity and operation. 


\section{Discussion}

Soil erosion and the restoration of arable land after the excessive use of chemical fertilisers can be improved by switching to organic farming, and restoration is generally ensured by the use of biofertilisers as well as by restoring the biological components of the soil. Cyanobacteria, fulfilling many different functions in the soil ecosystem, can be considered to be as promising objects in agrobiotechnology to produce biofertilisers. It is known that the absorption activity of plant root systems leads to an increased outflow of nitrogenous metabolites from the soil. The replenishment of this pool can be maintained by the high activity of the cyanobacterial nitrogenase complex. The study of the phototrophic microorganism biodiversity in the rice fields of Kazakhstan and the isolation of nitrogenfixing cyanobacteria from water, soil, algal mat, and plant samples was carried out to search for active strains of great practical interest.

The observed rich biodiversity of microalgae and cyanobacteria in the algoflora of the rice fields of the Kyzylorda region, with the characteristic seasonality of the species encountered, is certainly primarily related to the hydrological regime and soil properties, as well as the rice cultivation phase, the use of agrotechnical methods of rice cultivation, and seasonal temperature phenomena. Thus, during the period characterised by increased rice development, increasing shading of the water surface is observed, leading to a noticeable change in the ratio of the green species number, and they are replaced by shade-tolerant species of blue-green algae and diatoms, which form continuous films on the bottom of the rice fields.

The study of the morphological characteristics of the isolated strains J-14, K-31, J-8, J-1, and SH-12 allowed us to determine their affiliation to the orders Nostocales and Oscillatoriales, and through the analysis of phylogenetically similar species, they were identified as follows: Trichormus variabilis K-31 (MZ079356), Cylindrospermum badium J-8 (MZ079357), Nostoc sp. J-14 (MZ079360), Oscillatoria brevis SH-12 (MZ090011), and Tolypothrix tenuis J-1 (MZ079361).

An examination of the ability of the isolated heterocystous cyanobacteria to grow on a nitrogen-free nutrient medium, the heterocysts formation on a filament, and the nitrogenase activity of the strains under these conditions showed that all the strains examined could grow on a nitrogen-free medium. The results indicate a difference in the productivity of the representatives of the order Nostocales on a nitrogen-free medium. The cells of Trichormus variabilis K-31 and Nostoc sp. J-14 showed the highest productivity among the strains studied. The ability of all cultures examined to grow on a medium without a nitrogen source already indicates the presence of nitrogen-fixing activity in the isolated cyanobacterial cultures. However, compared to the control, a significant prolongation of the lag phase was observed on a nitrogen-free medium, which is apparently related to the adaptation of the cells to these conditions and the subsequent differentiation of some vegetative cells into heterocysts, with a corresponding shift in all phases of microbial population development. As is known, the formation of heterocysts begins after about $20 \mathrm{~h}$ of nitrogen starvation. This is because the genes for nitrogen fixation (nif) are expressed about 18-24 h after nitrogen deprivation [49].

Thus, the registration of the number of heterocysts in our studies showed that an increase in the number of heterocysts was observed in all cultures on a nitrogen-free medium, despite a slight decrease in the growth rate. Our results confirm the influence of nitrogen availability for cyanobacterial cells on the frequency of heterocyst formation and the species specificity of this factor. According to data in the literature, in the absence of a nitrogen source in the culture medium, $5-10 \%$ of the cells of the filaments of nitrogen-fixing cyanobacteria differentiate into heterocysts within about $24 \mathrm{~h}$ [50]. Heterocysts supply the vegetative cells with fixed nitrogen and receive carbohydrates from them in return [51,52]. This mutual exchange of balanced nutrients is regulated at the gene level to ensure their optimal growth and adaptation for long-term survival. At the same time, the genes responsible for heterocyst differentiation control their ratio to the number of vegetative cells on the filaments, ensuring an adequate balance between fixation by vegetative cells and nitrogen fixation by heterocysts. Thus, the NtcA-regulated patD gene is reported to 
control the ratio of heterocysts relative to vegetative cells on the filaments of Anabaena sp. PCC 7120 [53]. It should be noted that according to our results, the frequency of heterocyst formation was even significantly higher under nitrogen deficiency in the medium in some strains. Thus, in the filamentous cyanobacterium Trichormus variabilis K-31, 15-20 cells differentiated into heterocysts with an average initial frequency of $8.2 \pm 1.8$ vegetative cells per heterocyst, indicating the species specificity of this factor.

Subsequently, five isolated cyanobacterial strains were tested for their nitrogenase activity, including Oscillatoria brevis SH-12. Although this strain does not form heterocysts, according to recent data, the ability to fix nitrogen is characteristic not only of heterocystous strains, but also of those in which the processes of nitrogen molecule reduction and photosynthesis are separated in time and regulated by a circadian rhythm [54]. Based on the experiments, it was found that four of the five isolated cyanobacterial strains have some ability to fix nitrogen. Consequently, the best results were obtained for representatives of the order Nostocales. The strains Trihormus variabilis K-31 and Nostoc sp. J-14 had the highest nitrogen fixation activity. In contrast to the existing data on the nitrogenase activity of species of the genus Oscillatoria [55], we could not detect nitrogenase activity in the cells of Oscillatoria brevis $\mathrm{SH}-12$ in our study.

The activation of the process of nitrogen fixation is not only closely linked to the pool of nitrogen in the medium, but also depends on various external factors, including the content of various heavy metals. The process of nitrogen fixation is ensured by the work of a complex enzyme with several subunits and substrates called nitrogenase, which contains a metal in its active centre, and undoubtedly depends on their concentrations in the medium. Depending on the metal contained in the active centre, three types of nitrogenase are distinguished: Mo-nitrogenase (Mo), V-nitrogenase (V), and Fe-nitrogenase (Fe). In this context, it was advisable to investigate the effects of different Mo and Fe concentrations on the nitrogenase activity of the isolated strains and to select the optimal concentrations. For this purpose, two productive strains of the cyanobacteria Trihormus variabilis K-31 and Nostoc sp. J-14, which were proven to be the most active in previous studies, were selected.

The results obtained evidenced the stimulating effect of certain concentrations of the investigated metals on the cyanobacterial nitrogenase activity. The best results in the study of nitrogenase activity of Trichormus variabilis K-31 were obtained when it was exposed to Mo at a concentration of $1 \mu \mathrm{mol}$ and $10 \mu \mathrm{mol} \mathrm{Fe}$.

Thus, according to the research results, it was found that a certain amount of each metal studied has a stimulating effect on the operation of nitrogenase. According to the available literature data, nitrogenase responds to the availability of Fe and Mo in the media [56]. In our studies, the best results were obtained for both cyanobacterial cultures in the variants of the experiment with Mo at a concentration of $1 \mu \mathrm{mol}$ and $10 \mu \mathrm{mol} \mathrm{Fe}$. The results obtained confirm the presence of both types of nitrogenases in the cyanobacterial isolates studied. It is known that in such cases when the Mo concentration in the medium becomes limited, the work of alternative nitrogenases is expressed [57,58]. Thus, when Mo availability is higher, an increased efficiency of Mo nitrogenase is observed compared to V- and Fe-dependent enzymes [59]. In contrast to another metal studied, Mo is involved in nitrogen metabolism only in cyanobacterial cells and, although the cellular requirement for Mo is very low, this metal plays an essential role in the functioning of nitrogenase, the key element in nitrogen fixation [60]. A deficiency of Mo, which is part of the Fe-Mo cofactor of the enzyme, leads to a decrease in nitrogen fixation despite higher heterocyst and pigment concentrations [61]. When molybdate is excluded from the medium and vanadate is absent, the nitrogenase genes nif 1 and onf are expressed in heterocysts. However, since they cannot produce nitrogenase, these nitrogen-depleted cells produce a very high frequency of heterocysts and overexpress nitrogenase genes $[62,63]$. Our observations suggest the stimulatory effect of Mo on the activation of the enzyme. Increasing the Mo concentration to $1 \mu \mathrm{mol}$ increases the activity of nitrogenase. The results obtained correlate with the data available in the literature. Thus, according to the data presented, the growth rate of $A$. variabilis was almost the same under the influence of $\mathrm{V}$ and Mo, but the catalytic efficiency of the alternative 
nitrogenase was significantly lower than that of the MoFe-nitrogenase [64]. It was also found that the activity of VFe-nitrogenase in Azotobacter was about 1.5-fold lower than that of MoFe-nitrogenase under the same cultivation conditions [65].

Iron plays an equally important role in the process of nitrogen fixation. As is known, nitrogen fixation is an Fe-dependent process, since the nitrogenase complex contains $38 \mathrm{Fe}$ atoms per holoenzyme [66]. Among the strains examined, nitrogenase activity was significantly higher after Fe addition in the culture of Trichormus variabilis K-31 (4.2 nmol ethylene $\mathrm{mg}^{-1} \mathrm{DW} \mathrm{h}^{-1}$ ) compared to Nostoc sp. J-14 (3.8 nmol ethylene $\left.\mathrm{mg}^{-1} \mathrm{DW} \mathrm{h}^{-1}\right)$. At the same time, among the concentrations that were studied, $10 \mu \mathrm{mol}$ was optimal, a lower concentration $(1 \mu \mathrm{mol})$ was not effective enough, and a high concentration $(15 \mu \mathrm{mol})$ had a toxic effect, leading to negative changes in culture growth and low nitrogen fixation. The need for Fe in nitrogen reduction processes is related to the fact that these processes require Fe both in enzymes and for the ferredoxin-mediated provision of the restorative energy of photosynthesis or respiration [67]. Nitrogen fixation metabolism requires the synthesis of Fe and Fe-Mo subunits. In nitrate reduction (either from nitrogen fixation or from an external source), Fe is directly involved in nitrite reductase and, as a ferredoxin cofactor, for nitrate reductase. An iron limitation has been reported to reduce nitrate reductase levels in algae [68]. The entire pathway of nitrogen reduction (from either dinitrogen or nitrate) requires a flux of reducing agents from photosynthesis, resulting in an increased cellular demand for these Fe compounds [69]. It has been reported that nitrogen-fixing cyanobacteria require up to 10 -fold more Fe than the same species growing at the same rate on nitrates $[70,71]$.

The chosen concentrations of these metals were optimal for both nitrogen fixation and photosynthesis. At the same time, as expected, the addition of Fe in a nitrogen-free medium compared to Mo increased the photosynthetic activity of both cyanobacterial strains compared to control A (Allen medium without $\mathrm{N}$ source). It is known that Fe is necessary as a redox catalyst in photosynthesis and nitrogen assimilation for electron transfer and the formation of NADPH. Iron deficiency can reduce the concentration of chlorophyll and carotenoid in the cells of phototrophic microorganisms [5,72].

\section{Conclusions}

The broad spectrum of activity of cyanobacteria and their importance for the biosphere and the economy of humankind are good reasons to study and understand their diversity, conservation, and use in the interest of our society. Nitrogen-fixing cyanobacteria, for example, which have the simplest nutrient requirements in nature, make an enormous contribution to the nitrogen cycle and, thus, to the greening of agriculture. Maintaining an equilibrium of nitrogen input into the soil as a result of the process of nitrogen fixation is crucial for maintaining soil fertility over long periods. Although a large amount of data has been collected today on the diversity of cyanobacteria in aquatic and soil ecosystems, the search for new strains of cyanobacteria that have great potential for agricultural biotechnology and the replenishment of microbial collections is very important and relevant. This paper presents the results of isolating new nitrogen-fixing cyanobacterial strains and studying their photosynthetic and nitrogenase activities, as well as the prospects for stimulating their nitrogenase activity with two metals important for the process of nitrogen fixation. The optimal concentrations for cyanobacterial growth and stimulation of nitrogenase activity were determined. 


\begin{abstract}
Author Contributions: Conceptualization, A.K.S. and B.D.K.; methodology, A.K.S.; software, S.I.A.; validation, S.A. and J.W; formal analysis, A.I.T. and M.O.B.; investigation, B.K.Z.; resources, B.D.K. and J.W.; data curation, H.B., A.I.T., and S.A.; writing-original draft preparation, A.K.S.; writing—review and editing, B.D.K. and S.I.A.; visualization, Y.K.L. and J.-S.C.; supervision, S.I.A.; project administration, A.K.S. and S.I.A.; funding acquisition, Y.K.L. and A.K.S. All authors have read and agreed to the published version of the manuscript.
\end{abstract}

Funding: This research has been funded by the Ministry of Education and Science of the Republic of Kazakhstan in the framework of the projects: AP08052402 and AP09260077. J.W. was funded by Science and Technology Partnership Program, Ministry of Science and Technology of China (KY202001017) and Tianjin Synthetic Biotechnology Innovation Capacity Improvement Project: TSBICIP-IJCP-001-03 S.A. would like to thank the Distinguished Scientists Fellowship Program, King Saud University, Saudi Arabia, for their support. Y.K.L., J.-S.C., and S.I.A. were supported by the joint grant from Russian Science Foundation and MOST (Taiwan) (no: 22-44-08001). The results of part (Results) were obtained within the state assignment of the Ministry of Science and Higher Education of the Russian Federation (project No. 121033000136-4).

Institutional Review Board Statement: Not applicable.

Informed Consent Statement: Not applicable.

Data Availability Statement: The data are available from the corresponding authors upon reasonable request.

Conflicts of Interest: The authors declare no competing financial interest.

\title{
References
}

1. Sundararaman, M.; Subramanian, G.; Averal, H.I.; Akbarsha, M.A. Evaluation of the Bio-Activity of Marine Cyanobacteria on Some Biochemical Parameters of Rat Serum. Phytother. Res. 1996, 10, 9-12. [CrossRef]

2. Kaushik, B.D.; Venkataraman, G.S. Effect of algal inoculation on the yield and vitamin c content of two varieties of tomato. Plant Soil 1979, 52, 135-137. [CrossRef]

3. Choudhary, K.K. Occurrence of Nitrogen-Fixing Cyanobacteria during Different Stages of Paddy Cultivation. Bangladesh J. Plant Taxon. 2011, 18, 73-76. [CrossRef]

4. Sadvakasova, A.K.; Kossalbayev, B.D.; Zayadan, B.K.; Kirbayeva, D.K.; Alwasel, S.; Allakhverdiev, S.I. Potential of Cyanobacteria in the Conversion of Wastewater to Biofuels. World J Microbiol Biotechnol 2021, 37, 140. [CrossRef] [PubMed]

5. Zayadan, B.; Usserbayeva, A.; Bolatkhan, K.; Akmukhanova, N.; Kossalbayev, B.; Baizhigitova, A.; Los, D. Screening of Isolated and Collection Strains Of Cyanobacteria On Productivity For Determining Their Biotechnological Potential. Eur. J. Entomol. 2018, 55, 121-130. [CrossRef]

6. Mahmud, K.; Makaju, S.; Ibrahim, R.; Missaoui, A. Current Progress in Nitrogen Fixing Plants and Microbiome Research. Plants 2020, 9, 97. [CrossRef]

7. Venkataraman, G.S. Blue-Green algae for rice production. FAO Soil Bull. 1981, 16, 33-42. Available online: https: / / www.fao.org/ 3/i5199e/I5199E.pdf (accessed on 1 January 2022).

8. Shashirekha, S.; Uma, L.; Subramanian, G. Phenol Degradation by the Marine Cyanobacterium Phormidium Valderianum BDU 30501. J. Ind. Microbiol. Biotech. 1997, 19, 130-133. [CrossRef]

9. Bolatkhan, K.; Kossalbayev, B.D.; Zayadan, B.K.; Tomo, T.; Veziroglu, T.N.; Allakhverdiev, S.I. Hydrogen Production from Phototrophic Microorganisms: Reality and Perspectives. Int. J. Hydrog. Energy 2019, 44, 5799-5811. [CrossRef]

10. Kossalbayev, B.D.; Tomo, T.; Zayadan, B.K.; Sadvakasova, A.K.; Bolatkhan, K.; Alwasel, S.; Allakhverdiev, S.I. Determination of the Potential of Cyanobacterial Strains for Hydrogen Production. Int. J. Hydrog. Energy 2020, 45, 2627-2639. [CrossRef]

11. Sadvakasova, A.K.; Kossalbayev, B.D.; Zayadan, B.K.; Bolatkhan, K.; Alwasel, S.; Najafpour, M.M.; Tomo, T.; Allakhverdiev, S.I. Bioprocesses of Hydrogen Production by Cyanobacteria Cells and Possible Ways to Increase Their Productivity. Renew. Sustain. Energy Rev. 2020, 133, 110054. [CrossRef]

12. Bolatkhan, K.; Sadvakasova, A.K.; Zayadan, B.K.; Kakimova, A.B.; Sarsekeyeva, F.K.; Kossalbayev, B.D.; Bozieva, A.M.; Alwasel, S.; Allakhverdiev, S.I. Prospects for the Creation of a Waste-Free Technology for Wastewater Treatment and Utilization of Carbon Dioxide Based on Cyanobacteria for Biodiesel Production. J. Biotechnol. 2020, 324, 162-170. [CrossRef] [PubMed]

13. Issa, A.A.; Abd-Alla, M.H.; Ohyama, T. Nitrogen Fixing Cyanobacteria: Future Prospect; IntechOpen: London, UK, 2014; ISBN 978-953-51-1216-7.

14. Singh, J.S.; Kumar, A.; Rai, A.N.; Singh, D.P. Cyanobacteria: A Precious Bio-Resource in Agriculture, Ecosystem, and Environmental Sustainability. Front. Microbiol. 2016, 7, 529. [CrossRef] [PubMed]

15. Durner, J.; Böhm, I.; Knörzer, O.C.; Böger, P. Proteolytic Degradation of Dinitrogenase Reductase from Anabaena Variabilis (ATCC 29413) as a Consequence of ATP Depletion and Impact of Oxygen. J. Bacteriol. 1996, 178, 610. [CrossRef] [PubMed] 
16. Gallon, J.R. Reconciling the Incompatible: $\mathrm{N}_{2}$ Fixation and $\mathrm{O}_{2}$. New Phytol. 1992, 122, 571-609. Available online: https: / / www.jstor.org/stable/2557427 (accessed on 1 February 2022). [CrossRef]

17. Berman-Frank, I.; Lundgren, P.; Falkowski, P. Nitrogen Fixation and Photosynthetic Oxygen Evolution in Cyanobacteria. Res. Microbiol. 2003, 154, 157-164. [CrossRef]

18. UTEX-Culture Collection of Algae at The University of Texas at Austin. Available online: https://utex.org/products/bg-11 -medium?variant=30991786868826 (accessed on 25 February 2022).

19. UTEX-Culture Collection of Algae at The University of Texas at Austin. Available online: https://utex.org/products/allenmedium?variant=30991788507226 (accessed on 25 February 2022).

20. UTEX-Culture Collection of Algae at The University of Texas at Austin. Available online: https://utex.org/products/boldbasal-medium (accessed on 25 February 2022).

21. Huynh, M.; Serediak, N. Algae Identification Field Guide; Agriculture and Agri-Food Canada: Ottawa, ON, Canada, 2006; p. 40. ISBN 978-1-100-18308-4.

22. Bellinger, E.G.; Sigee, D.C. Freshwater Algae: Identification and Use as Bioindicators; John Wiley \& Sons: Hoboken, NJ, USA, 2011; p. 284. ISBN 978-1-119-96432-2.

23. Wilson, K.M.; Schembri, M.A.; Baker, P.D.; Saint, C.P. Molecular Characterization of the Toxic Cyanobacterium Cylindrospermopsis Raciborskii and Design of a Species-Specific PCR. Appl. Environ. Microbiol. 2000, 66, 332-338. [CrossRef]

24. Dale, R.K.; Pedersen, B.S.; Quinlan, A.R. Pybedtools: A Flexible Python Library for Manipulating Genomic Datasets and Annotations. Bioinformatics 2011, 27, 3423-3424. [CrossRef]

25. De Lillo, A.; Ashley, F.P.; Palmer, R.M.; Munson, M.A.; Kyriacou, L.; Weightman, A.J.; Wade, W.G. Novel Subgingival Bacterial Phylotypes Detected Using Multiple Universal Polymerase Chain Reaction Primer Sets. Oral Microbiol. Immunol. 2006, 21, 61-68. [CrossRef]

26. Walters, W.; Hyde, E.R.; Berg-Lyons, D.; Ackermann, G.; Humphrey, G.; Parada, A.; Gilbert, J.A.; Jansson, J.K.; Caporaso, J.G.; Fuhrman, J.A.; et al. Improved Bacterial 16S RRNA Gene (V4 and V4-5) and Fungal Internal Transcribed Spacer Marker Gene Primers for Microbial Community Surveys. mSystems 2015, 1, e00009-15. [CrossRef]

27. Hiraishi, A.; Kamagata, Y.; Nakamura, K. Polymerase Chain Reaction Amplification and Restriction Fragment Length Polymorphism Analysis of 16S RRNA Genes from Methanogens. J. Ferment. Bioeng. 1995, 79, 523-529. [CrossRef]

28. Johansen, J.R.; Mareš, J.; Pietrasiak, N.; Bohunická, M.; Zima, J.; Štenclová, L.; Hauer, T. Highly Divergent 16S RRNA Sequences in Ribosomal Operons of Scytonema Hyalinum (Cyanobacteria). PLoS ONE 2017, 12, e0186393. [CrossRef] [PubMed]

29. Sanger, F.; Nicklen, S.; Coulson, A.R. DNA Sequencing with Chain-Terminating Inhibitors. Proc. Natl. Acad. Sci. USA 1977, 74, 5463-5467. [CrossRef] [PubMed]

30. Lu, G.; Moriyama, E.; Lu, G.; Moriyama, E.N. Vector NTI, a Balanced All-in-One Sequence Analysis Suite. Brief. Bioinform. 2005, 5 , 378-388. [CrossRef]

31. Tsarenko, P.M.; Borysova, O.V.; Korkhovyi, V.I.; Blume, Y.B. High-Efficiency Ukrainian Strains of Microalgae for Biodiesel Fuel Production (Overview). Open Agric. J. 2020, 14, 209-218. [CrossRef]

32. UTEX-Culture Collection of Algae at The University of Texas at Austin. Available online: https://utex.org/products/bg-11-nmedium (accessed on 12 December 2021).

33. Thajuddin, N.; Subramanian, G. Cyanobacterial Biodiversity and Potential Applications in Biotechnology. Curr. Sci. 2005, 89, 47-57.

34. Alekseev, A.A.; Yakovleva, O.V.; Matorin, D.N. The Fluorescence Methods for an Assessment Photosynthetic Capacity of Plants under the Anthropogenic Load. AIP Conf. Proc. 2018, 2041, 050013. [CrossRef]

35. Kumar, D.; Singh, H.; Raj, S.; Soni, V. Chlorophyll a Fluorescence Kinetics of Mung Bean (Vigna Radiata L.) Grown under Artificial Continuous Light. Biochem. Biophys. Rep. 2020, 24, 100813. [CrossRef]

36. Tsygankov, A.A.; Serebryakova, L.T.; Rao, K.K.; Hall, D.O. Acetylene Reduction and Hydrogen Photoproduction by Wild-Type and Mutant Strains of Anabaena at Different $\mathrm{CO}_{2}$ and $\mathrm{O}_{2}$ Concentrations. FEMS Microbiol. Lett. 1998, 167, 13-17. [CrossRef]

37. Ritchie, R.J. Consistent Sets of Spectrophotometric Chlorophyll Equations for Acetone, Methanol and Ethanol Solvents. Photosynth. Res. 2006, 89, 27-41. [CrossRef]

38. Wellburn, A.R. The Spectral Determination of Chlorophylls a and b, as Well as Total Carotenoids, Using Various Solvents with Spectrophotometers of Different Resolution. J. Plant Physiol. 1994, 144, 307-313. [CrossRef]

39. Bennett, A.; Bogorad, L. Complementary Chromatic Adaptation in a Filamentous Blue-Green Alga. J. Cell. Biol. 1973, 58, 419-435. [CrossRef] [PubMed]

40. Newman, L.; Duffus, A.L.J.; Lee, C. Using the Free Program MEGA to Build Phylogenetic Trees from Molecular Data. Am. Biol. Teach. 2016, 78, 608-612. [CrossRef]

41. Johansen, J.R.; Bohunická, M.; Lukešová, A.; Hrčková, K.; Vaccarino, M.A.; Chesarino, N.M. Morphological and Molecular Characterization within 26 Strains of the Genus Cylindrospermum (Nostocaceae, Cyanobacteria), with Descriptions of Three New Species. J. Phycol. 2014, 50, 187-202. [CrossRef]

42. Zulkefli, N.S.; Hwang, S.-J. Heterocyst Development and Diazotrophic Growth of Anabaena Variabilis under Different Nitrogen Availability. Life 2020, 10, 279. [CrossRef] [PubMed]

43. Gollerbakh, M.M.; Kosinskaya, E.K.; Polyanskii, V.I. Opredelitel' Presnovodnykh Vodoroslei SSSR. Vyp. 2. Sinezelenye Vodorosli; Identification Guide of Freshwater Algae of the USSR. Iss. 2. Blue-Green Algae; Sovetskaya Nauka: Moscow, Russia, 1953. 
44. Hauer, T.; Bohunická, M.; Johansen, J.R.; Mareš, J.; Berrendero-Gomez, E. Reassessment of the Cyanobacterial Family Microchaetaceae and Establishment of New Families Tolypothrichaceae and Godleyaceae. J. Phycol. 2014, 50, 1089-1100. [CrossRef] [PubMed]

45. Munawar, S.; Khan, A. Occurrence of blooms of blue green algae from the coast of Buleji, Karachi, Pakistan. Int. J. Biol. Res. 2017, $5,31-34$.

46. Komárek, J.; Zapomělová, E. Planktic Morphospecies of the Cyanobacterial Genus Anabaena= Subg. Dolichospermum-1. Part: Coiled Types. Fottea 2007, 7, 1-31. [CrossRef]

47. Tamura, K.; Peterson, D.; Peterson, N.; Stecher, G.; Nei, M.; Kumar, S. MEGA5: Molecular Evolutionary Genetics Analysis Using Maximum Likelihood, Evolutionary Distance, and Maximum Parsimony Methods. Mol. Biol. Evol. 2011, 28, $2731-2739$. [CrossRef] [PubMed]

48. Gladkikh, A.S.; Belykh, O.I.; Klimenkov, I.V.; Tikhonova, I.V. Nitrogen-Fixing Cyanobacterium Trichormus Variabilis of the Lake Baikal Phytoplankton. Microbiology 2008, 77, 726-733. [CrossRef]

49. Walsby, A.E. Cyanobacterial Heterocysts: Terminal Pores Proposed as Sites of Gas Exchange. Trends Microbiol. 2007, 15, 340-349. [CrossRef]

50. Kumar, K.; Mella-Herrera, R.A.; Golden, J.W. Cyanobacterial Heterocysts. Cold Spring Harb. Perspect. Biol. 2010, 2, a000315. [CrossRef] [PubMed]

51. Singh, P.; Khan, A.; Srivastava, A. Chapter 16-Heterocyst and Akinete Differentiation in Cyanobacteria: A View toward Cyanobacterial Symbiosis. In Advances in Cyanobacterial Biology; Singh, P.K., Kumar, A., Singh, V.K., Shrivastava, A.K., Eds.; Academic Press: Cambridge, MA, USA, 2020; pp. 235-248. ISBN 978-0-12-819311-2.

52. Allakhverdiev, E.S.; Khabatova, V.V.; Kossalbayev, B.D.; Zadneprovskaya, E.V.; Rodnenkov, O.V.; Martynyuk, T.V.; Maksimov, G.V.; Alwasel, S.; Tomo, T.; Allakhverdiev, S.I. Raman Spectroscopy and Its Modifications Applied to Biological and Medical Research. Cells 2022, 11, 386. [CrossRef] [PubMed]

53. Wang, L.; Lin, G.-M.; Niu, T.-C.; Zhang, S.-R.; Zhang, J.-Y.; Tang, G.-F.; Chen, W.; Zhang, C.-C. PatD, a Gene Regulated by NtcA, Is Involved in the Optimization of Heterocyst Frequency in the Cyanobacterium Anabaena sp. Strain PCC 7120. J. Bacteriol. 2019, 201, e00457-19. [CrossRef] [PubMed]

54. Magnuson, A. Heterocyst Thylakoid Bioenergetics. Life 2019, 9, 13. [CrossRef]

55. Bergman, B.; Gallon, J.R.; Rai, A.N.; Stal, L.J. N 2 Fixation by Non-Heterocystous Cyanobacteria. FEMS Microbiol. Rev. 1997, 19, 139-185. [CrossRef]

56. Seefeldt, L.C.; Hoffman, B.M.; Dean, D.R. Mechanism of Mo-Dependent Nitrogenase. Annu. Rev. Biochem. $2009,78,701$. [CrossRef]

57. Betancourt, D.A.; Loveless, T.M.; Brown, J.W.; Bishop, P.E. Characterization of Diazotrophs Containing Mo-Independent Nitrogenases, Isolated from Diverse Natural Environments. Appl. Environ. Microbiol. 2008, 74, 3471-3480. [CrossRef]

58. Bothe, H.; Schmitz, O.; Yates, M.G.; Newton, W.E. Nitrogen Fixation and Hydrogen Metabolism in Cyanobacteria. Microbiol. Mol. Biol. Rev. 2010, 74, 529-551. [CrossRef]

59. Berrendero, E.; Valiente, E.F.; Perona, E.; Gómez, C.L.; Loza, V.; Muñoz-Martín, M.Á.; Mateo, P. Nitrogen Fixation in a NonHeterocystous Cyanobacterial Mat from a Mountain River. Sci. Rep. 2016, 6, 30920. [CrossRef]

60. Raymond, J.; Siefert, J.L.; Staples, C.R.; Blankenship, R.E. The Natural History of Nitrogen Fixation. Mol. Biol. Evol. 2004, 21, 541-554. [CrossRef] [PubMed]

61. Esteves-Ferreira, A.A.; Cavalcanti, J.H.F.; Vaz, M.G.M.V.; Alvarenga, L.V.; Nunes-Nesi, A.; Araújo, W.L. Cyanobacterial Nitrogenases: Phylogenetic Diversity, Regulation and Functional Predictions. Genet. Mol. Biol. 2017, 40, 261-275. [CrossRef]

62. Thiel, T.; Pratte, B. Alternative Nitrogenases in Anabaena Variabilis: The Role of Molybdate and Vanadate in Nitrogenase Gene. Adv. Microbiol. 2013, 3, 87-95. [CrossRef]

63. Zahalak, M.; Pratte, B.; Werth, K.; Thiel, T. Molybdate Transport and Its Effect on Nitrogen Utilization in the Cyanobacterium Anabaena Variabilis ATCC 29413: Molybdate Transport in Anabaena. Mol. Microbiol. 2004, 51, 539-549. [CrossRef]

64. Kentemich, T.; Danneberg, G.; Hundeshagen, B.; Bothe, H. Evidence for the Occurrence of the Alternative, Vanadium-Containing Nitrogenase in the Cyanobacterium Anabaena Variabilis. FEMS Microbiol. Lett. 1988, 51, 19-24. [CrossRef]

65. Miller, R.W.; Eady, R.R. Molybdenum and Vanadium Nitrogenases of Azotobacter Chroococcum. Low Temperature Favours N2 Reduction by Vanadium Nitrogenase. Biochem. J. 1988, 256, 429-432. [CrossRef]

66. Seefeldt, L.C.; Yang, Z.-Y.; Lukoyanov, D.A.; Harris, D.F.; Dean, D.R.; Raugei, S.; Hoffman, B.M. Reduction of Substrates by Nitrogenases. Chem. Rev. 2020, 120, 5082-5106. [CrossRef]

67. Devadasu, E.; Chinthapalli, D.K.; Chouhan, N.; Madireddi, S.K.; Rasineni, G.K.; Sripadi, P.; Subramanyam, R. Changes in the Photosynthetic Apparatus and Lipid Droplet Formation in Chlamydomonas Reinhardtii under Iron Deficiency. Photosynth. Res. 2019, 139, 253-266. [CrossRef]

68. Rueter, J.G.; Petersen, R.R. Micronutrient Effects on Cyanobacterial Growth and Physiology. N. Z. J. Mar. Freshw. Res. 1987, 21, 435-445. [CrossRef]

69. Yadavalli, V.; Jolley, C.C.; Malleda, C.; Thangaraj, B.; Fromme, P.; Subramanyam, R. Alteration of Proteins and Pigments Influence the Function of Photosystem I under Iron Deficiency from Chlamydomonas Reinhardtii. PLoS ONE 2012, 7, e35084. [CrossRef]

70. Devadasu, E.; Pandey, J.; Dhokne, K.; Subramanyam, R. Restoration of Photosynthetic Activity and Supercomplexes from Severe Iron Starvation in Chlamydomonas Reinhardtii. Biochim. Biophys. Acta (BBA) Bioenerg. 2021, 1862, 148331. [CrossRef] [PubMed] 
71. Huang, M.; Zhang, J.-Y.; Zeng, X.; Zhang, C.-C. C-Di-GMP Homeostasis Is Critical for Heterocyst Development in Anabaena sp. PCC 7120. Front. Microbiol. 2021, 12, 793336. [CrossRef] [PubMed]

72. Rochaix, J.-D. Reprint of: Regulation of Photosynthetic Electron Transport. Biochim. Biophys. Acta (BBA) Bioenerg. 2011, 1807, 878-886. [CrossRef] [PubMed] 